VIVIAN CAROLINA FERREIRA MUNIZ

ANÁLISE DA FUNDAMENTAÇÃO DA AVALIAÇÃO DO CICLO DE VIDA CONSEQUENCIAL 
VIVIAN CAROLINA FERREIRA MUNIZ

\section{ANÁLISE DA FUNDAMENTAÇÃO DA AVALIAÇÃO DO CICLO DE VIDA CONSEQUENCIAL}

Dissertação apresentada à Escola Politécnica da Universidade de São Paulo para obtenção do título de Mestre em Engenharia 
VIVIAN CAROLINA FERREIRA MUNIZ

\section{ANÁLISE DA FUNDAMENTAÇÃO DA AVALIAÇÃO DO CICLO DE VIDA CONSEQUENCIAL}

Dissertação apresentada à Escola Politécnica da Universidade de São Paulo para obtenção do título de Mestre em Engenharia

Área de concentração:

Engenharia Química

Orientador:

Professor Gil Anderi da Silva 
Este exemplar foi revisado e alterado em relação à versão original, sob responsabilidade única do autor e com a anuência de seu orientador.

São Paulo, de julho de 2012.

Assinatura do autor

Assinatura do orientador

Muniz, Vivian Carolina Ferreira

Análise da fundamentação da avaliação do ciclo de vida consequencial / V.C.F. Muniz. -- ed.rev. -- São Paulo, 2012.

$87 \mathrm{p}$.

Dissertação (Mestrado) - Escola Politécnica da Universidade de São Paulo. Departamento de Engenharia Química.

1. Ciclo de vida (Avaliação) I. Universidade de São Paulo. Escola Politécnica. Departamento de Engenharia Química II. t. 


\section{DEDICATÓRIA}

Aos meus pais. 


\section{AGRADECIMENTOS}

A Deus, por sempre iluminar o meu caminho.

Ao meu orientador Prof. Gil Anderi da Silva, pelo conhecimento transmitido, pelo apoio, pelas conversas e por sempre acreditar no meu trabalho.

Ao Professor Luiz Kulay, pelos ricos comentários e participação na Banca do Exame de Qualificação e na Comissão Julgadora da Dissertação de Mestrado. Pela ajuda no tema e sugestões ao longo do desenvolvimento deste trabalho.

Aos professores Patrícia Matai e Eduardo Licco, pela participação na Banca do Exame de Qualificação e pelas suas sugestões que tornaram mais completa esta dissertação.

Ao Professor José Adolfo, pela participação na Comissão Julgadora da Apresentação de Mestrado e pelas suas recomendações quanto às correções do trabalho.

Aos colegas de mestrado, Eduardo, Maritza e Rafael.

Meus agradecimentos ao Alex Nogueira, pela grande ajuda nos temas burocráticos e por sempre estar disposto a ajudar.

Aos meus pais, Suely e Celso, que são a base da minha educação, obrigada pelo apoio e carinho. Aos meus irmãos, Celso e Camila, parceiros de toda a vida.

Ao Jesus, amor da minha vida, que me apoia e me acompanha nos objetivos que traço.

Às amigas Paola e Priscilla, pelo companheirismo, pelos ouvidos, conselhos e motivação.

Aos meus supervisores Prof. Adilson Pires Afonso e Cláudio de Brito Sanches, por entenderem a importância deste mestrado e por me liberarem de valiosas horas no trabalho.

Meu agradecimento especial à amiga Thaís Mourão, por me incentivar a começar, continuar e finalizar este trabalho, serei sempre grata pela sua amizade.

$\mathrm{E}$ agradeço a todos que de maneira direta ou indireta colaboraram para a finalização do meu mestrado. 
Feliz é o homem que acha sabedoria, e o homem que adquire conhecimento

(Provérbios 3:13) 
RESUMO....................................................................................... iii

ABSTRACT .................................................................................. iv

LISTA DE FIGURAS ......................................................................... v

LISTA DE TABELAS .................................................................. vi

LISTA DE ABREVIATURAS ............................................................. vii

1 INTRODUÇÃO ........................................................................... 1

2 OBJETIVO ….................................................................................. 3

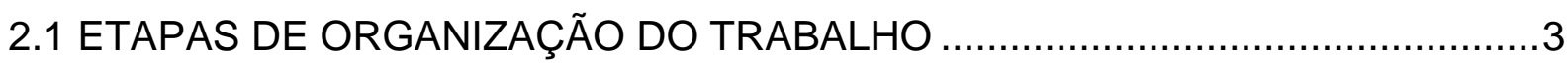

3 METODOLOGIA ...................................................................... 4

4 REVISÃO BIBLIOGRÁFICA ........................................................ 5

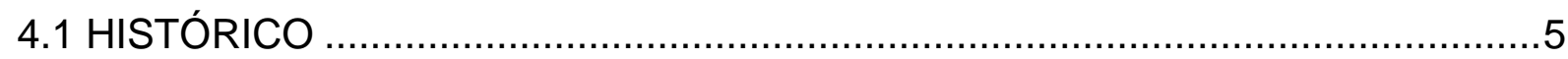

4.2 DIFERENÇA CONCEITUAL ENTRE AS METODOLOGIAS .............................

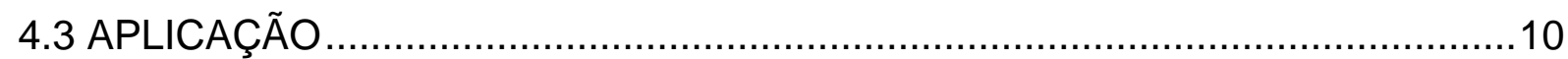

4.4 ANÁLISE TEMPORAL ENTRE AS METODOLOGIAS .......................................12

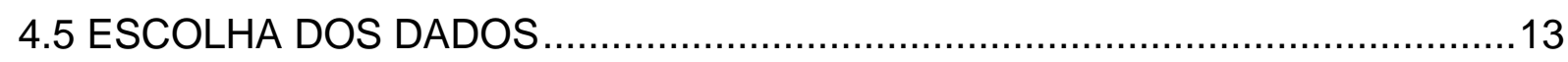

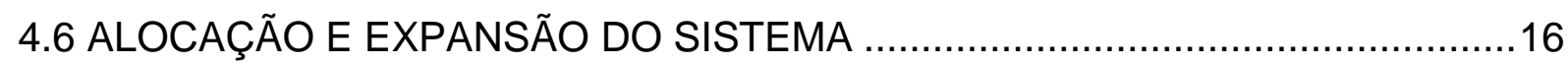

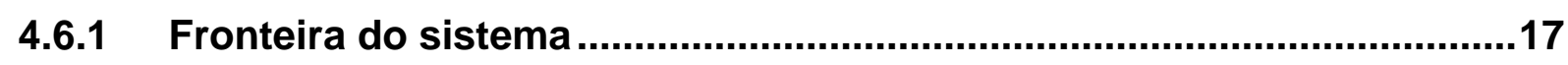

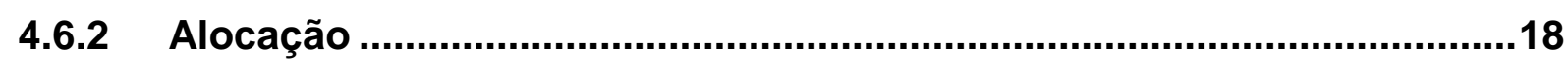

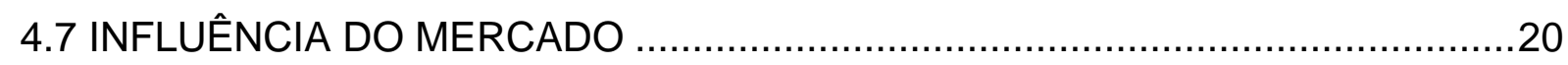

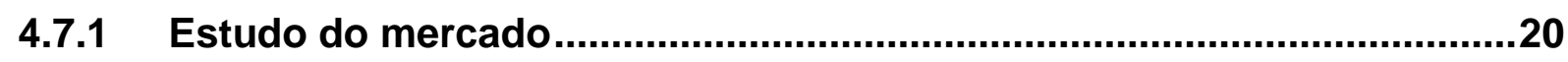

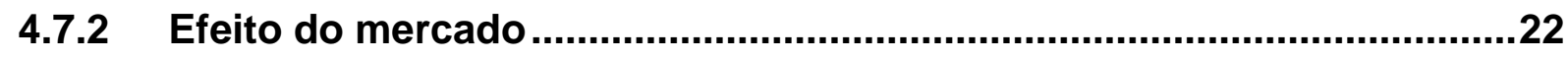

4.7.3 Modelagem econômica ...........................................................................26

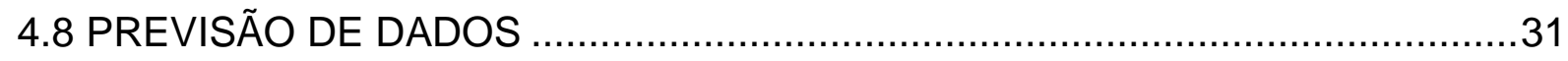


5 RESULTADOS E DISCUSSÕES

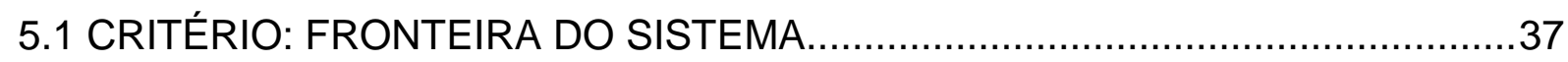

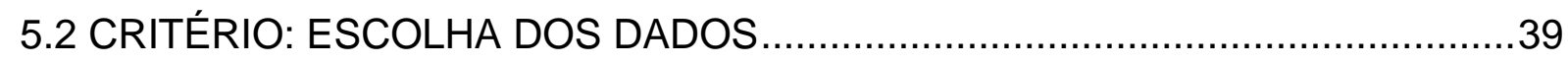

5.3 CRITÉRIO: ALOCAÇÃO E EXPANSÃO DO SISTEMA …................................40

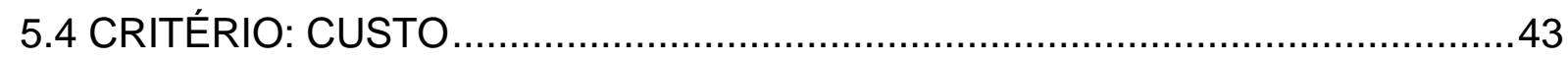

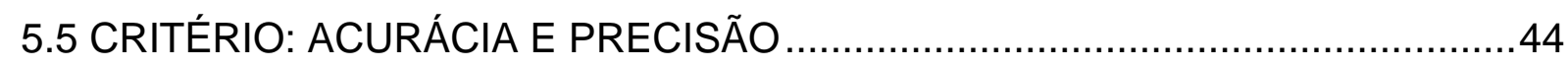

5.6 CRITÉRIO: SIMPLICIDADE DE EXECUÇÃO …................................................48

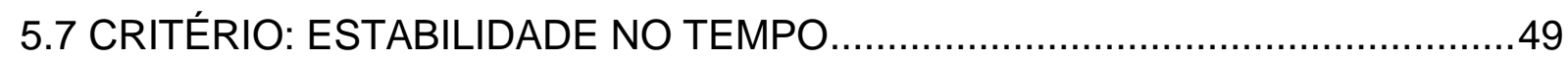

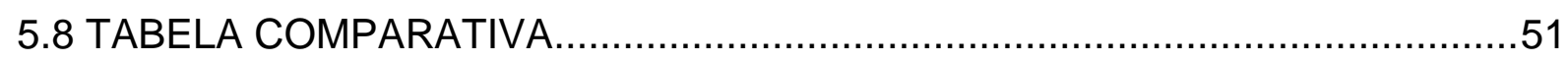

6 CONCLUSÕES .......................................................................... 53

6.1 RECOMENDAÇÕES PARA TRABALHOS FUTUROS ….................................54

7 REFERENCIAS BIBLIOGRÁFICAS .......................................... 55

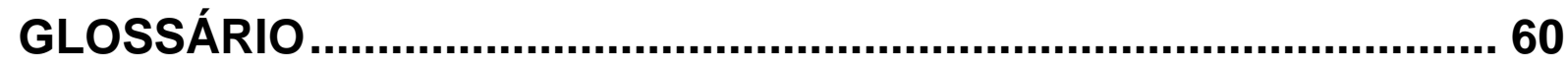

ANEXO A - Procedimento para identificação da tecnologia marginal 64

ANEXO B - Critérios de seleção para métodos de previsão........... 65

ANEXO C - Aplicações da ACV Consequencial............................. 66

ANEXO D - Estudo de caso ACV Consequencial ............................ 68 


\section{RESUMO}

O presente trabalho apresenta 0 resultado da análise sobre o novo foco da ferramenta Avaliação do Ciclo de Vida (ACV): a ACV consequencial. O método convencional da ACV - ACV atribucional - tem sido criticado pelo fato de não suportar decisões baseadas em cenários futuros. Como resposta a esta deficiência, a ACV consequencial surge como uma proposta a um método mais apropriado que avalia consequências ambientais futuras provocadas pelo uso do produto em estudo. O enfoque consequencial apresenta uma abordagem nova da ACV; ainda existem visões distintas e, algumas vezes, divergentes desta abordagem na comunidade internacional da ACV, seja na área acadêmica, seja fora dela. Neste trabalho são apresentadas e discutidas as diferenças, limitações, vantagens e desvantagens entre essas duas ferramentas. Foi possível observar que na realização de um estudo de ACV de um produto ou serviço, a definição do objetivo e escopo do estudo é fundamental para a escolha de qual enfoque da ACV será aplicado. Observou-se, também, que há limitações metodológicas tanto para a ACV atribucional como para a ACV consequencial. No caso da ACV atribucional, por exemplo, há incertezas com relação à escolha subjetiva do método de alocação de co-produtos. Já no caso da ACV consequencial, os resultados podem ser mais sensíveis e mais suscetíveis a incertezas devido às inclusões de estudo da tendência e projeções do mercado para a escolha dos dados e tecnologias marginais, e para a previsão de dados.

Palavras-chave: Avaliação do ciclo de vida; ACV atribucional; ACV consequencial. 


\section{ABSTRACT}

The main purpose of this master is to present the analysis results on the Life Cycle Assessment (LCA) new approach: consequential LCA. The conventional method of LCA - the attributional approach - has been criticized for not supporting decisions based on future scenarios. In response to this deficiency, the consequential LCA appears as a proposal to a more appropriate method to evaluate future environmental consequences caused by the use of the product under study. As the consequential LCA represents a new approach to LCA, there still are divergent opinions within the LCA international community. In this work, there are shown and discussed the main differences, limitations between these two approaches. It was observed that in conducting an LCA study of a product or service, the definition of the objective and scope of the study is fundamental to the choice of which LCA methodology is applied. It was also observed that there are methodological limitations to both attributional LCA and consequential LCA. In case of attributional LCA, for example, there are uncertainties related to the subjective choice of the allocation method of co-products. In case of consequential LCA, the results may be more sensitive and more susceptible to uncertainties due to inclusions of trend studies and market projections for choosing marginal data and technologies, and for forecast data.

Keywords: Life cycle assessment, attributional LCA, consequential LCA. 


\section{LISTA DE FIGURAS}

Figura 1 - Diferença conceitual entre ACV atribucional e consequencial (adaptado de WEIDEMA, 2003).

Figura 2 - Propagação das consequências de mudanças feitas pelo tomador de decisão (EKVALL; WEIDEMA, 2004).

Figura 3 - Dados que refletem mudanças (adaptado de AZAPAGIC e CLIF, 1999). 14

Figura 4 - Modelo para expansão do sistema e delimitação em relação ao coproduto (adaptado de WEIDEMA; FRESS; NIELSEN, 1999).

Figura 5 - Importância dos mecanismos de feedback positivo e negativo nas diferentes fases da tecnologia (SANDÉN; KARLSTRÖM, 2007).

Figura 6 - Diferença entre os ciclos considerando a alocação e a expansão do sistema.

Figura 7 - Relação de acurácia e precisão para analisar os dois enfoques da ACV (Adaptado de Weidema (2011).

Figura 8 - Árvore de decisão mostrando o procedimento de cinco passos (adaptado de Weidema, Fress e Nielsen (1999).

Figura 9 - Estrutura esquemática das pastas de solda de chumbo e estanho e das pastas de solda sem chumbo para a modelagem consequencial (EKVALL; ANDRAE, 2006).

Figura 10 - Estrutura esquemática das pastas de solda de chumbo e estanho e das pastas de solda sem chumbo para a modelagem atribucional (EKVALL; ANDRAE, 2006) .70 


\section{LISTA DE TABELAS}

Tabela 1 - Técnicas para métodos de previsão de dados e as suas limitações. ......35

Tabela 2 - Relevância dos métodos de previsão e sua dependência com o horizonte temporal e complexidade. ........................................................ 36

Tabela 3 - Análise das características da ACV atribucional e consequencial...........53 


\section{LISTA DE ABREVIATURAS}

ABNT - Associação Brasileira de Normas Técnicas

ACV - Avaliação do Ciclo de Vida

AICV - Avaliação de Impacto do Ciclo de Vida

CALCAS - Co-ordination Action for innovation in Life-Cycle Analysis for Sustainability

CGE - Computable Global Equilibrium

EPD - Environmental Product Declaration

ICV - Inventário do Ciclo de Vida

ILUC - Indirect Land Use Change

ISO - International Organization for Standardization

MMMR-PE - Multi-Market, Multi-Regional Partial Equilibrium Modelling

MRI - Midwest Research Institute

PBA - Printed Board Assembly

PE - Partial Equilibrium Modelling

PWB - Printed Wiring Board 


\section{INTRODUÇÃO}

Mudanças climáticas e outras ameaças ambientais têm estado mais em foco durante os últimos anos. Para o conhecimento desses desafios, considerações ambientais têm que ser integradas a um número de diferentes tipos de decisões feitas tanto por administrações empresariais, individuais e públicas, como para formadores de opinião. Com isso, informações sobre aspectos ambientais de diferentes sistemas são então necessárias e muitas ferramentas e indicadores para avaliar e referenciar impactos ambientais de diferentes sistemas têm sido desenvolvidos (FINNVEDEN et al, 2009). Dentre as várias técnicas de gestão ambiental (avaliação de risco, avaliação de desempenho ambiental, auditoria ambiental e avaliação de impacto ambiental), uma que tem se destacado com este objetivo é a Avaliação do Ciclo de Vida (ACV) (ABNT, 2009a).

A ACV é uma técnica de gestão ambiental utilizada para avaliar o desempenho ambiental de um produto ou serviço ao longo de todo o seu ciclo de vida. O ciclo de vida é o conjunto de etapas encadeadas e sucessivas que incluem: a obtenção dos recursos naturais; as etapas de transformação necessárias à fabricação do produto principal (o qual é o objetivo de estudo); uso; distribuição e disposição final do produto no meio ambiente (RIBEIRO, 2009)

Governantes de diversos países encorajam o uso da ACV. Cada vez mais, a ACV está se tornando um elemento chave na política ambiental ou em ações voluntárias na União Europeia, Estados Unidos, Japão, Coréia, Canadá, Austrália e em países em desenvolvimento como Brasil, Índia e China (GUINÉE et al., 2011).

Juntamente com a popularidade da ACV, veio também usos mais criativos desta ferramenta. É possível encontrar atualmente estudos de ACV em incineração de resíduos, materiais de construção, sistemas militares, e turismo. Ademais, enquanto os estudos recentes são restritos a apenas algumas categorias de aspectos ambientais (como demanda de energia cumulativa e resíduo sólido), podese encontrar aumento nos estudos com impactos mais complexos e uma ampliação nos estudos considerando impactos econômicos e sociais. Finalmente, observa-se 0 aumento na sofisticação de modelos fundamentais, desde uma proporcionalidade simples das relações de emissões provindas de atividades e impactos dessas 
emissões, até os modelos dinâmicos, regionalizados, não-lineares que incluem modelos econômicos, estudos de restauração de ecossistemas, e mais (GUINÉE et al., 2011).

Dentro deste histórico de novos usos da ACV, surge um novo enfoque que combina o cálculo de ACV com métodos de modelagem econômica. Este novo enfoque é denominado ACV Consequencial. Segundo Earles e Halog (2011), a ACV consequencial representa a convergência da ACV com modelos econômicos. Há mais de um século, economistas tentaram desenvolver um método para quantificar os impactos das relações econômicas - tais como efeitos de substituição, economias de escala, elasticidades de suprimento e demanda, entre outros. Para os autores, a ACV consequencial integra vários fenômenos econômicos com a modelagem ambiental do ciclo de vida de produtos e sistemas tecnológicos.

Como o enfoque consequencial apresenta uma abordagem nova da ACV, ainda existe visões distintas e, algumas vezes, divergentes desta abordagem na comunidade internacional da ACV, seja na área acadêmica, seja fora dela.

Nesse contexto, decidiu-se com este trabalho submeter à comunidade brasileira de ACV uma análise da fundamentação deste novo enfoque. 


\section{OBJETIVO}

O objetivo geral deste trabalho é o estudo aprofundado da ferramenta ACV consequencial.

Os objetivos específicos desta dissertação são: (i) analisar comparativamente as ferramentas ACV consequencial e ACV atribucional identificando as diferenças conceituais entre as duas, seus pontos fortes e fracos quanto à aplicação, e suas limitações; (ii) disponibilizar os conhecimentos adquiridos sobre ACV consequencial para uso da comunidade brasileira de ACV para norteamento de decisões na aplicação da ACV consequencial em trabalhos futuros.

\subsection{ETAPAS DE ORGANIZAÇÃO DO TRABALHO}

O presente trabalho está organizado em quatro seções, sendo elas: Metodologia, Revisão Bibliográfica, Resultados e Discussões, e Conclusões.

$\mathrm{Na}$ seção de Metodologia são listadas as atividades executadas que tornaram possível a análise sobre ACV consequencial.

$\mathrm{Na}$ seção de Revisão Bibliográfica são apresentados os conceitos e diferenças registrados na literatura quanto aos enfoques atribucional e consequencial da ACV.

A seção de Resultados e Discussões contém a análise dos conceitos adquiridos na Revisão Bibliográfica e, junto com as Conclusões, posiciona o leitor frente ao uso dos dois enfoques da ACV.

$\mathrm{Na}$ seção de Conclusões, além de um extrato da Discussão, ainda são mencionadas sugestões para Futuros Trabalhos que poderão dar sequência ao trabalho aqui apresentado.

Após a seção de Conclusões são apresentadas as Referências Bibliográficas. 


\section{METODOLOGIA}

Para realizar a análise das fundamentações da ACV consequencial, foram executadas as seguintes atividades:

- Pesquisa bibliográfica visando o levantamento dos diferentes conceitos e formas de abordagem da ACV consequencial;

- Estudo aprofundado dos conhecimentos obtidos nessa pesquisa;

- Levantamento prévio de um conjunto de critérios para a análise entre os enfoques da ACV: atribucional e consequencial;

- Análise das duas fundamentações utilizando os critérios selecionados;

- Compilação da análise em tabela comparativa.

Para a pesquisa bibliográfica foram examinados artigos de periódicos científicos, teses e dissertações, resumos de congressos nacionais e internacionais no intuito de compor um conjunto sólido de referências bibliográficas para esta dissertação. Foram usadas palavras-chaves como: metodologia de ACV, ACV consequencial, ACV atribucional, expansão do sistema, alocação, dados marginais, tecnologias marginais, aplicação de ACV; entre outras.

Feito isso, as referências foram separadas em temas para melhor realizar os estudos, apresentados na seção de Revisão Bibliográfica.

Após o levantamento das referências bibliográficas e o estudo aprofundado das mesmas, foi definido que a análise entre as duas fundamentações seria feita com base em critérios pré-determinados.

As justificativas para a seleção desses critérios e a discussão dos mesmos quando relacionados aos enfoques atribucional e consequencial da ACV são apresentados na seção Resultados e Discussões.

A compilação das análises, o fechamento do trabalho e as sugestões para trabalhos futuros estão expostos na seção Conclusões. 


\section{REVISÃO BIBLIOGRÁFICA}

\subsection{HISTÓRICO}

O surgimento da ACV deu-se na Europa e nos Estados Unidos no fim da década de 1960 e início da década de 1970, durante a primeira crise do petróleo. Segundo Chehebe (1997), a crise do petróleo gerou uma busca frenética por formas alternativas de energia e despertou o mundo para a necessidade de melhor utilização de seus recursos naturais. Nessa época, vários estudos foram realizados buscando avaliar os processos produtivos e racionalizar o consumo de fontes energéticas.

Desde então, vários trabalhos têm sido realizados não apenas enfocando a questão energética, mas também aspectos ligados às questões ambientais, incluindo estimativas de emissões sólidas, gasosas ou líquidas.

O primeiro registro de um estudo de ACV data de 1965 no qual a Coca-Cola custeou um estudo realizado pelo MRI (Midwest Research Institute) cujo objetivo era a comparação de diferentes tipos de embalagens para refrigerantes e a determinação de qual delas apresentava índices mais adequados de emissão para o meio ambiente e melhor desempenho com relação à preservação de recursos naturais (CHEHEBE, 1997).

De acordo com a ABNT ISO NBR 14040 (2009a), a ACV enfoca os aspectos ambientais e os impactos ambientais potenciais (uso de recursos naturais, incluindo o solo, e as consequências de liberações para o meio ambiente) ao longo de todo o ciclo de vida de um produto, desde a aquisição das matérias-primas, passando pela produção, uso, tratamento pós-uso, reciclagem até a disposição final.

São quatro as fases que compõem um estudo de ACV: (i) a fase de definição de objetivo e escopo, (ii) a fase de análise de inventário, (iii) a fase de avaliação de impactos, e (iv) a fase de interpretação. O escopo de uma ACV, incluindo a fronteira do sistema e o nível de detalhamento, depende do objeto e do uso pretendido para o estudo. A profundidade e a abrangência da ACV podem variar consideravelmente dependendo do objetivo do estudo em particular. A fase de análise de inventário do ciclo de vida (ICV) é a segunda fase de uma ACV. Trata-se 
de um inventário dos dados de entrada/saída associados ao sistema em estudo. Essa fase envolve a coleta dos dados necessários para o alcance dos objetivos do estudo em questão. A fase de avaliação de impacto do ciclo de vida (AICV) é a terceira fase da ACV. O objetivo da AICV é prover informações adicionais para ajudar na avaliação dos resultados do ICV de um sistema de produto, visando ao melhor entendimento de sua significância ambiental. A interpretação do ciclo de vida é a fase final do procedimento de ACV, na qual os resultados de um ICV e/ou de uma AICV, ou de ambos, são sumarizados e discutidos como base para conclusões, recomendações e tomada de decisão de acordo com a definição de objetivo e escopo (ABNT, 2009a).

O desenvolvimento da metodologia de estudos de ACV ganhou impulso na década de 90 do século passado e sinalizou para uma distinção entre dois tipos de métodos: a ACV atribucional e a ACV consequencial.

No seio da comunidade internacional da ACV, o método convencional da ACV - ACV atribucional - tem sido criticado pelo fato de não suportar decisões baseadas em cenários futuros. Como resposta a esta deficiência, a ACV consequencial surge como uma proposta de método mais apropriado para avaliar consequências ambientais futuras provocadas pelo uso do produto em estudo (SANDÉN; KARLSTRÖM, 2007).

Os primeiros registros do surgimento da ACV consequencial datam do início da década de 1990 com Heintz e Baisnée (1992) e Weidema (1993). A ideia que a alocação de co-produtos pode ser evitada pela expansão do sistema foi levantada por Tillman et al (1991) com respeito à incineração de resíduos e, mais tarde, em um cenário mais abrangente, abordado por Heintz e Baisnée (1992). Os autores apresentaram um trabalho no Workshop "Life Cycle Assessment" ocorrido em Leiden no ano de 1991 sobre fronteiras do sistema (WEIDEMA; FRESS; NIELSEN, 1999). Outro autor, Weidema (1993), propõe na sua tese de doutorado uma tipologia para as avaliações de ciclo de vida baseada, entre outros aspectos, na aplicação para informação versus decisão em mudanças.

Em outubro de 2001, na cidade de Cincinnati, ocorreu um workshop de três dias com o objetivo de discutir os dados de inventário de ciclo de vida para a geração de eletricidade (The International Workshop on electricity data for life cycle inventories). Entre os objetivos abordados neste workshop, incluiu-se a formalização e o esclarecimento de terminologias (CURRAN; MANN; NORRIS, 2005). 
Autores anteriores (FINNVEDEN et al., 2005; TILLMAN, 2000; EKVALL; TILLMAN; MOLANDER, 2005) rotulavam as avaliações de ciclo de vida como sendo "retrospectiva" e "prospectiva", ou "descritiva" e "orientada na mudança". O grupo de discussão presente no workshop determinou que a distinção central a ser considerada fosse a diferenciação entre ACV "atribucional" e "consequencial".

Segundo, foi exposto neste Workshop que a ACV atribucional visa responder à pergunta: "como as correntes (de poluentes, recursos e trocas entres processos) fluem em um determinado espaço temporal?". Por outro lado, a ACV consequencial visa responder à pergunta: "como os fluxos irão mudar em resposta às tomadas de decisões?" (CURRAN; MANN; NORRIS, 2005).

Finalmente o grupo notou que os inventários "retrospectivos" são inventários sobre situações anteriores, ou mudanças/decisões que ocorreram no passado, enquanto que os inventários "prospectivos" dispõem sobre situações futuras ou mudanças/decisões que irão ocorrer. Um inventário pode ser:

- prospectivo e atribucional: como as correntes fluirão no futuro?

- prospectivo e consequencial: como uma decisão futura mudará os fluxos?

- retrospectivo e atribucional: como as correntes fluíram no passado?

- retrospectivo e consequencial: como uma decisão tomada no passado mudou os fluxos? (CURRAN; MANN; NORRIS, 2005).

A formalização da ACV consequencial serviu não apenas para padronizar o seu nome, a sua denominação, mas também oficializou a distinção entre os dois tipos de ACVs. Pode-se dizer que o congresso de Cincinnati, oficializou a denominação "consequencial", reconhecendo a sua existência e uso.

\subsection{DIFERENÇA CONCEITUAL ENTRE AS METODOLOGIAS}

Para ilustrar a diferença conceitual entre a ACV atribucional e consequencial, Weidema (2003) propôs o desenho esquemático circular apresentado na Figura 1. Nesta figura, as fatias e regiões delimitadas por linhas tracejadas representam as cargas ambientais calculadas por cada tipo de ferramenta utilizada no estudo. 
As Figuras representam a carga ambiental total do planeta em um dado intervalo de tempo. Na Figura 1a, a área hachurada representa a carga ambiental de um sistema de produto, calculada pela ACV atribucional. Na Figura 1b, a área hachurada representa as potenciais variações da carga ambiental do ciclo de vida do produto em estudo (WEIDEMA, 2003).

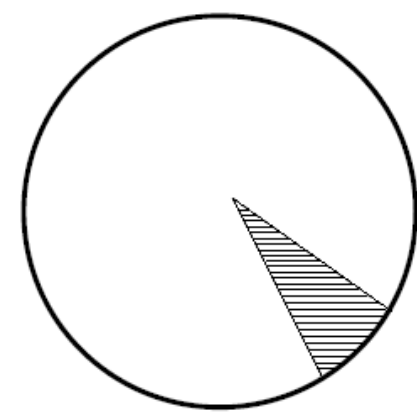

1a - Atribucional

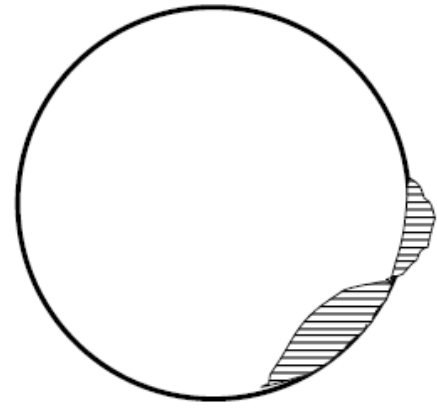

$1 b-$ Consequencial

Figura 1 - Diferença conceitual entre ACV atribucional e consequencial (adaptado de WEIDEMA, 2003).

A relevância da ACV atribucional tem sido questionada, pois o seu objetivo final, mesmo para a identificação dos pontos de maiores aspectos ambientais (hot spots) e declarações de produtos, é o de aperfeiçoar os sistemas estudados. Weidema (2003) defende que mesmo na identificação dos hot spots pela ACV atribucional, caso sejam identificadas várias opções para melhoria do sistema, uma avaliação consequencial ainda seria necessária para analisar as consequências da implementação dessas melhorias. O mesmo ocorre para a declaração de produtos; caso esta seja usada pelos consumidores para fazer escolhas entre vários produtos, uma análise baseada nas consequências ambientais dessas opções, e não, em impactos históricos causados pelos produtos, deveria ocorrer.

Para alguns autores, tais como Guinée et al. (2001) apud Finnveden (2009), não há uma maneira objetiva de se isolar uma atividade humana da tecnosfera, como ilustrado na Figura 1a, uma vez que todas as atividades humanas e sistemas de produtos estão, em última análise, interligados. 
Segundo Ekvall e Weidema (2004), quando o objetivo é descrever as consequências de mudanças, não é usualmente suficiente, e talvez nem ao menos relevante, mapear os materiais no produto investigado desde o berço - desde a extração ou geração dos recursos naturais. A decisão de comprar um produto não implica necessariamente no aumento da extração de recursos naturais. Em termos gerais, as consequências de uma ação não propagam somente pelo ciclo de vida, mas por todos os sistemas econômicos e tecnológicos nas cadeias das relações de causa e efeito, assemelhando-se às ondas causadas por uma pedra atirada em um lago. A Figura 2 transcreve essa analogia.

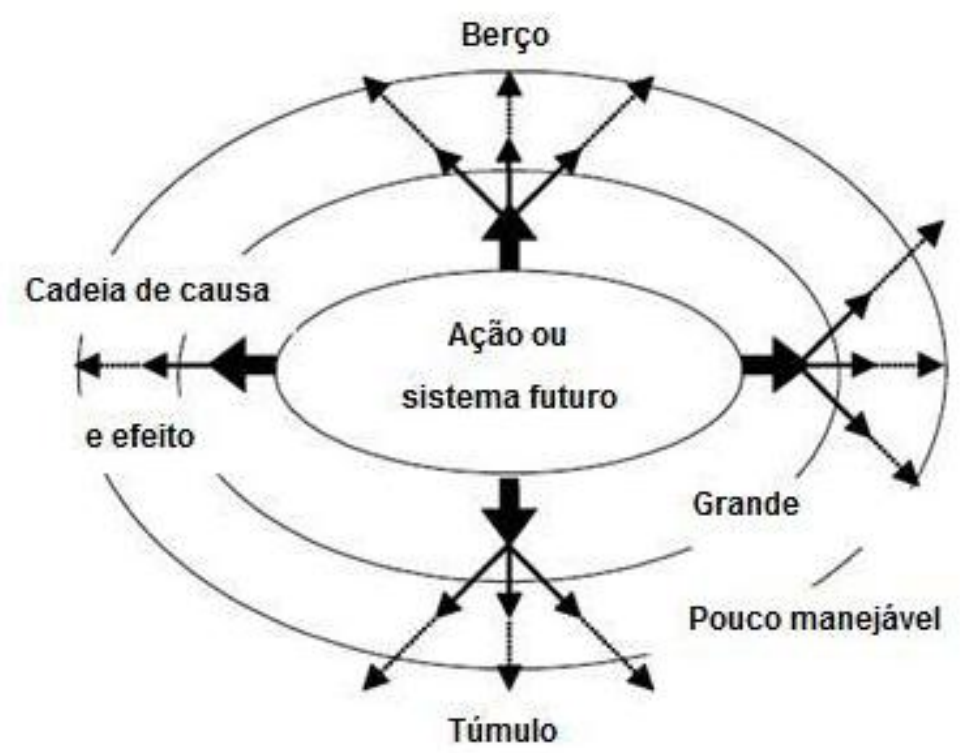

Figura 2 - Propagação das consequências de mudanças feitas pelo tomador de decisão (EKVALL; WEIDEMA, 2004).

O ponto de partida natural de um ICV consequencial de uma decisão específica é a decisão em si, isto é, o ponto onde a pedra atinge a água na Figura 2. O ICV consequencial descreve como a decisão afeta a atividade tecnológica, tanto diretamente onde a decisão é implementada e seus efeitos secundários sobre o uso de produtos intermediários. O inventário passa a descrever como é esperado que esta decisão afete, por exemplo, a produção destes produtos intermediários, bem como o uso dos produtos intermediários em outros processos. Ademais, o ICV consequencial descreve como é esperado que essas mudanças afetem, por sua vez, outros processos de produção, o uso de energia, materiais e produtos em outras partes do sistema tecnológico, e os fluxos ambientalmente relevantes que se 
destinam ou originam das atividades afetadas. Assim, o modelo de ICV consequencial não é similar com o tradicional modelo de ICV, onde os principais fluxos materiais são descritos desde a extração de matéria-prima até o gerenciamento dos resíduos. Em vez disso, é um modelo de cadeias de relações casuais (EKVALL; WEIDEMA, 2004).

\subsection{APLICAÇÃO}

Muitas tentativas têm sido feitas para descrever quando os dois diferentes tipos de ACV são apropriados. Como as ferramentas possuem uma distinção no escopo e nas fronteiras, fica claro que as ACV consequencial e atribucional irão gerar diferentes informações ambientais. Alguns autores defendem que a escolha entre uma ACV consequencial e uma atribucional depende das razões pelas quais a ACV está sendo conduzida, com o enfoque atribucional sendo mais apropriado para o conhecimento sobre os aspectos ambientais dos produtos e o enfoque consequencial sendo mais apropriado para o suporte de decisões (TILLMAN, 2000). Também foi sugerido que a escolha entre uma ACV atribucional e uma consequencial depende das perspectivas éticas do tomador da decisão (EKVALL; TILLMAN; MOLANDER, 2005).

Como Tillman (2000), Lundie et al. (2007) apud Finnveden et al. (2009) defendem que a ACV consequencial deve ser usada como tomada de decisões, mas não quando as diferenças entre os resultados da ACV consequencial e da atribucional são pequenas. O autor também não recomenda o uso da ACV consequencial quando as incertezas na modelagem consequencial ultrapassam os conhecimentos adquiridos no estudo. Quando não há uma decisão a ser tomada, a ACV atribucional deve ser usada, pois é a ferramenta mais amplamente aplicada, e porque modelar as consequências de decisões não se torna justificável quando não há nenhuma decisão a ser tomada (FINNVEDEN et al, 2009).

Segundo Ekvall, Tillman e Molander (2005), uma limitação da ACV consequencial é relacionada com o fato de que a ACV é geralmente utilizada para propósitos de aprendizado, sem uma ação específica em mente. Não seria racional descrever as consequências de todas as possíveis ações em uma ACV 
consequencial. Quando nenhuma ação foi especificada, o profissional que esteja executando a ACV consequencial somente pode modelar a esfera de influência dos tomadores de decisão. Estas são as partes do sistema técnico que podem ser influenciadas pelos tomadores de decisão, tanto direta quanto indiretamente.

Por sua vez, Weidema (2003) argumenta que a ACV consequencial é mais relevante para tomadas de decisões; entretanto ele defende também que tal enfoque é mais relevante para aumentar o entendimento da cadeia de produção e para identificar os processos e relações mais importantes a serem melhorados. Quando uma ACV consequencial é aplicada para este propósito, o autor defende que ela pode criar uma boa base para a geração de ideias para as melhorias (WEIDEMA, 2003).

Outros autores defendem o uso da ACV consequencial para auxílio na escolha tecnológica para melhoria do processo em situações onde se buscam mudanças de larga escala, e em longo prazo. Segundo Sandén e Karlström (2007), a metodologia da ACV atribucional é desenvolvida para responder questões sobre impactos ambientais da produção atual (ou do histórico da produção) e uso de um produto ou mudanças no processo. Quando esta metodologia é usada (sem modificações) para prover respostas às questões sobre escolhas de estratégias tecnológicas, ou seja, decisões que não visam melhorar um processo com uma tecnologia ambiental existente, mas com o objetivo em longo prazo de mudança dos sistemas tecnológicos em larga escala, o resultado é de pouco valor e, no pior caso, interpretações do resultado podem ser drasticamente mal-entendidas.

A distinção entre a ACV consequencial e a atribucional é um exemplo de como as escolhas na fase de Definição de Objetivo e de Escopo de uma ACV podem influenciar escolhas metodológicas e de dados para as fases de inventário (ICV), e a fase de avaliação de impacto (AICV). Há também outras escolhas que são importantes. Guinée et al (2002) faz uma distinção similar em tipos de modelagem de ACV, no entanto inicia pelo discernimento de três tipos principais de decisões: escolhas ocasionais (em relação ao cumprimento pontual de uma função), escolhas estruturais (em relação a uma função que é fornecida regularmente), e escolhas estratégicas (em como fornecer uma função por um longo período de tempo ou mesmo por um período de tempo indefinido). Esses tipos diferentes de decisões podem requerer diferentes tipos de modelagem (atribucional ou consequencial) e 
diferentes tipos de dados, uma vez que eles têm diferentes escalas em termos de tempo e impactos (FINNVEDEN et al, 2009).

\subsection{ANÁLISE TEMPORAL ENTRE AS METODOLOGIAS}

Alguns autores (TILLMAN, 2000; EKVALL, 2002) definem a ACV atribucional como retrospectiva, focando sua análise em impactos ambientais históricos; sendo seu estudo relevante para um estado estático presente ou estados históricos recentes. Já a ACV consequencial é tida como prospectiva, e foca sua análise em impactos ambientais futuros. Assim, se presta a investigação de consequências ambientais futuras de uma decisão tomada hoje ou a especulação sobre as consequências de uma escolha futura.

De acordo com Sandén e Karlström (2007), esta diferença é uma questão de especificação de um ponto de partida temporal para o estudo, seja ele um tempo específico, um período de tempo, para qual este estudo seja válido, podendo ser, por exemplo, tanto em 1985 e 2005, como também em 2025.

Para a ACV atribucional, é possível investigar o desempenho de uma tecnologia ou produto em um estado estacionário diferente, por exemplo, um estado futuro (2025), um estado histórico (1985) ou um estado fictício caracterizado por um desempenho modificado e uma tecnologia ambiental distinta. Deste modo, pode-se dizer que a ACV atribucional pode ser prospectiva, já que estudos prospectivos não precisam ser necessariamente comparações de mudanças marginais de um estado atual. Por outro lado, a ACV atribucional pode também tratar de comparações de produtos e processos em estados estacionários futuros (SANDÉN; KARLSTRÖM, 2007).

Para a ACV consequencial, mesmo que este enfoque seja comumente usado para investigar as consequências ambientais futuras de uma decisão tomada no presente, em princípio, seria possível usar uma perspectiva orientada em uma mudança retrospectiva para rastrear as consequências ambientais de uma escolha histórica (por exemplo, em 1985) ou para especular sobre as consequências de uma escolha futura (por exemplo, em 2025). 
Segundo Sandén e Karlström (2007), se para o sistema estudado o volume de controle for estático, a ACV atribucional pode ser usada mesmo com a definição temporal de um ano futuro, como 2025. Se para o sistema estudado o volume de controle for dinâmico, a ACV consequencial pode ser usada mesmo com a definição temporal de um ano passado, como 1985.

\subsection{ESCOLHA DOS DADOS}

Os diferentes focos da ACV atribucional e consequencial são refletidos nas muitas escolhas metodológicas da ACV. Uma delas é a escolha entre os dados a serem usados na modelagem de subsistemas do ciclo de vida. Quais dados são mais relevantes para modelar um sistema depende do objetivo do estudo. Deve ser decidido onde usar um dado de um sistema específico e quando empregar um dado representando uma média de processos similares e onde usar dados representando um desempenho marginal (TILLMAN, 2000).

Os dados médios para um sistema são aqueles representando as cargas ambientais médias para produzir uma unidade do bem e/ou serviço do sistema. Os dados marginais representam dados realmente afetados por uma pequena mudança nas correntes de entrada e saída associados aos bens e/ou serviços de um sistema sobre as suas cargas ambientais (FINNVEDEN et al, 2009). Se a mudança estudada for grande, será necessário usar técnicas de cenários que incluam as mudanças sociais necessárias (WEIDEMA; FRESS; NIELSEN, 1999).

Segundo Curran, Mann, e Norris (2005), é a magnitude das decisões e de suas consequências que leva à definição de "marginal". Distúrbios ou perturbações marginais são perturbações infinitesimais. Um distúrbio marginal é infinitesimal na teoria, porém na prática é pequeno o suficiente para ser aproximado como um distúrbio infinitesimal. Isso requer que a resposta à perturbação seja proporcional à magnitude da perturbação.

Para Curran, Mann, e Norris (2005), consequências marginais são as respostas do sistema frente a um distúrbio marginal. Por exemplo, as consequências marginais de um pequeno aumento na demanda de eletricidade podem implicar em um discreto aumento nas emissões de poluentes e consumo de combustíveis. 
Para Azapagic e Clif (1999) um dos principais objetivos da ACV é comparar mudanças em torno de uma condição existente do sistema, seja ela uma variação pequena na composição do produto ou tecnologia, uma mudança substancial de matéria-prima ou condições de operação, ou uma mudança completa para um produto ou uma tecnologia totalmente diferente. Logo, mudanças em um sistema podem ser tanto marginais, como incrementais ou médias. Azapagic e Clif (1999) ilustram na Figura 3 a distinção entre esses três tipos de diferenças para o caso simples de uma única carga ambiental que varia com a taxa de provisão de saída de uma função.

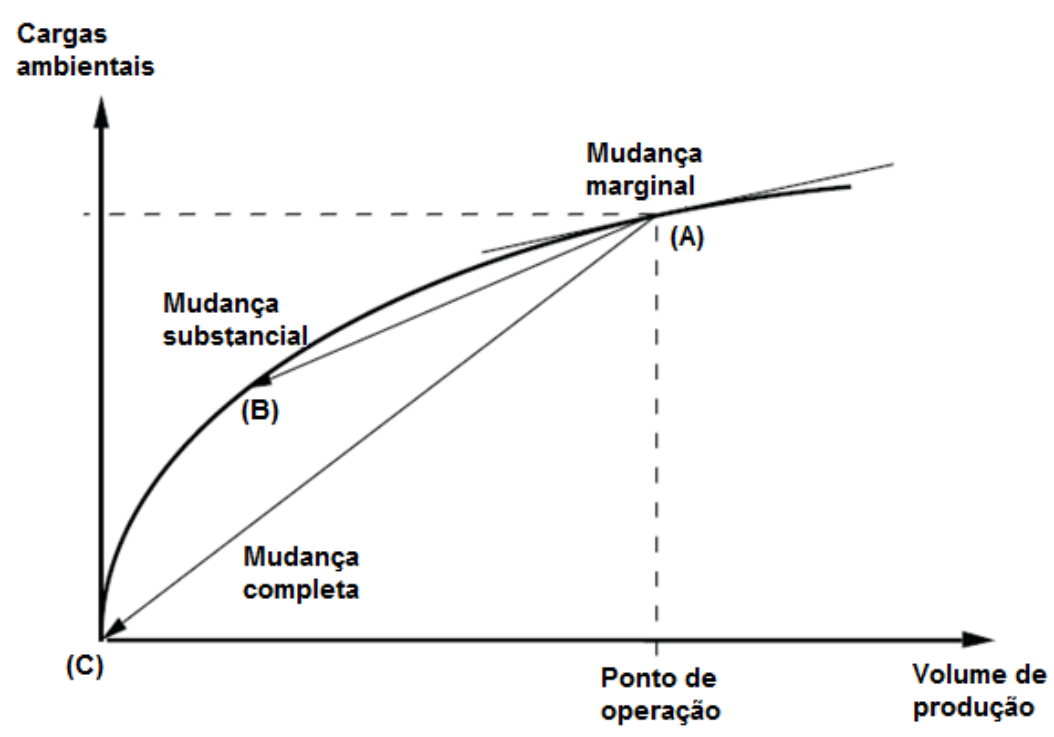

Figura 3 - Dados que refletem mudanças (adaptado de AZAPAGIC e CLIF, 1999).

O ponto A representa o "caso base", usualmente a operação atual na qual as mudanças serão consideradas. As mudanças marginais representam variações infinitesimais sobre a operação existente, representada pela tangente da curva no ponto A. Uma análise incremental descreve a mudança em um sistema de operação que corresponde ao deslocamento para um novo ponto de operação (B). Mudanças médias relacionam um deslocamento significante na operação do sistema; para o exemplo, uma eliminação completa da saída do sistema funcional, do volume de produção (ponto $\mathrm{C}$ ). Mudanças incrementais e médias são conjuntamente referenciadas como mudanças discretas (AZAPAGIC; CLIF, 1999). 
Segundo Azapagic e Clif (1999), para decidir qual a base de dados mais apropriada para determinado estudo, é necessário decidir qual o tipo de mudança deve ser considerada:

a) Mudanças marginais descrevem as mudanças que são suficientemente pequenas para serem aproximadas como infinitesimais e são, portanto, sempre lineares. Normalmente, uma análise marginal pode descrever variações de curto prazo na saída de um dado sistema, ou um desenvolvimento a longo prazo das tecnologias usadas no sistema. Um exemplo deste tipo de mudança é a comparação de diferentes rotas de gerenciamento de resíduos para um material específico que iria comprometer somente uma pequena fração da corrente de resíduo total. A análise marginal também é relevante em co-produtos e sistemas que envolvem reciclagem. Nestes, as saídas podem ser alteradas independentemente uma da outra, e o efeito das mudanças marginais independentes delas é observado como objeto de estudo. As mudanças marginais são de fato muito pequenas e não causam uma mudança no modo como o sistema é operado (AZAPAGIC; CLIF, 1999).

b) Mudanças incrementais são aplicáveis, por exemplo, para comparar produtos alternativos ou resíduos que representam uma proporção significativa da corrente de saída ou do resíduo processado, ou são aplicáveis ainda para mudanças substanciais na parte de um sistema de produto. Exemplos incluem o uso de uma, ou mais, unidades de processo diferentes em um arranjo de processos mais global ou, no caso de um incinerador de resíduos, mudanças nas condições de combustão e adição de um novo equipamento de controle de emissões, talvez usando diferentes energias ou materiais auxiliares. As mudanças incrementais também são relevantes se diferentes processos e produtos com funções similares são comparados dentro de uma mescla de tecnologias médias. Por exemplo, em caso de comparação de diferentes opções de manejo de resíduos, como a incineração e a reciclagem de um produto ou material específico (AZAPAGIC; CLIF, 1999).

c) Mudanças médias são aplicáveis quando são consideradas as mudanças fundamentais que iriam influenciar ou deslocar um grande número de tecnologias. Um exemplo para tal mudança seria a substituição para uma economia livre de cloro, a qual significaria a retirada de todos os produtos que contenham cloro, introduzindo uma mescla totalmente nova de tecnologias para a produção de produtos alternativos. Isso levaria posteriormente a mudanças discretas nas 
emissões dos processos, tais como a queima de resíduos para geração de energia (AZAPAGIC; CLIF, 1999).

Segundo Ekvall, Tillman e Molander (2005), nos casos de estudos de ACV consequencial, o sistema investigado deve idealmente incluir as atividades onde as mudanças mais importantes podem ser induzidas pelos tomadores de decisão. Atividades as quais somente podem afetar marginalmente devem ser modeladas usando dados marginais, enquanto que as atividades para as quais os tomadores de decisão podem fazer mudanças completas (por exemplo, sistemas futuros) devem ser modelados usando dados médios.

O uso de dados marginais é típico para o ICV consequencial, uma vez que a maioria das decisões possuem efeitos marginais em sistemas de grande produção. Um problema neste contexto é que pode ser difícil identificar as tecnologias onde efeitos marginais ocorrem (EKVALL; TILLMAN; MOLANDER, 2005).

Para os autores, um estudo de ACV baseado em dados médios claramente não reflete nenhum efeito marginal, ou seja, efeitos de mudanças pequenas no volume de produção. Em contraste a isto, pode-se esperar muitas ações que causam mudanças que são pequenas o suficiente para serem aproximadas como efeitos marginais na produção de materiais (como aço, alumínio, polietileno), energias motrizes (como eletricidade, óleo combustível pesado, petróleo), e serviços (como gerenciamento de resíduos) onde o volume de produção total é muito alto. Uma vez que os resultados da ACV atribucional não refletem as consequências de ações individuais, há um risco que o meio ambiente possa ser danificado pelas ações que são recomendadas com base na ACV atribucional.

A determinação das tecnologias marginais e, com isso, os dados marginais a serem usados em estudos de ACV consequencial, é apresentada nas seções seguintes.

\subsection{ALOCAÇÃO E EXPANSÃO DO SISTEMA}

Em relação a como lidar com a alocação de co-produtos, a ACV atribucional geralmente baseia-se, quando a alocação se faz necessária, em propriedades e características dos produtos e co-produtos, seja por massa, outro parâmetro físico 
ou mesmo, valor comercial. Na ACV consequencial, entretanto, a alocação é evitada pela expansão do sistema (se a subdivisão técnica do processo não for possível). Expandir o sistema significa que as entradas e saídas são inteiramente descritas para o produto de interesse (geralmente o produto principal). Subsequentemente, na ACV consequencial, o sistema de produto é expandido para incluir os produtos evitados (DALGAARD et al., 2008).

\subsubsection{Fronteira do sistema}

De acordo com a ABNT NBR ISO 14040 (2009a), a ACV é conduzida por meio da definição de modelos de sistemas de produto que descrevem os elementoschave de sistemas físicos. A fronteira do sistema define os processos elementares a serem incluídos no sistema. Idealmente, é conveniente que o sistema de produto seja modelado de tal forma que as entradas e saídas na sua fronteira sejam fluxos elementares. No entanto, não é necessário despender recursos na quantificação daquelas entradas e saídas que não irão alterar de forma significativa as conclusões gerais do estudo.

A escolha de elementos do sistema físico a ser modelado depende da definição do objetivo e escopo do estudo, de sua aplicação pretendida e públicoalvo, dos pressupostos adotados, das restrições de dados, e de custos e de critérios de corte. Convém que os modelos usados sejam descritos, e os pressupostos que embasaram aquelas escolhas sejam identificados. Convém que os critérios de corte usados em um estudo sejam claramente entendidos e descritos. Os critérios utilizados no estabelecimento da fronteira do sistema são importantes para o grau de confiança nos resultados de um estudo e para a possibilidade de se atingir seu objetivo (ABNT, 2009a).

$\mathrm{Na}$ delimitação do sistema para a ACV Consequencial, deve-se adicionar, além do ciclo de vida do produto a ser estudado, os ciclos de vidas dos produtos marginais definidos na etapa de estudo de mercado. 


\subsubsection{Alocação}

A alocação consiste na divisão adequada dos fatores de impacto do processo entre o produto principal e os subprodutos do sistema. A sua utilização se faz necessária, por exemplo, quando um sistema a ser estudado gera mais de um produto, emissão atmosférica gerada por meio de tratamento de resíduos ou ainda a reciclagem (RAMIREZ, 2009).

A ideia de que a alocação de co-produtos pode ser evitada pela expansão do sistema reforça o primeiro passo de identificação de processos compartilhados com outros sistemas descritos na norma ABNT NBR ISO 14044, onde se diz: O estudo deverá identificar os processos compartilhados com outros sistemas de produto e tratá-los de acordo com o procedimento apresentado a seguir:

Convém que a alocação seja evitada, sempre que possível, por meio de:

1) divisão dos processos elementares a serem alocados em dois ou mais subprocessos e coleta dos dados de entrada e saída relacionados a esses subprocessos;

2) expansão do sistema de produto de modo a incluir as funções adicionais relacionadas aos co-produtos, levando em consideração os requisitos de critérios de corte descritos na norma (ABNT, 2009b).

Ekvall e Finnveden (2001) afirmam que, em muitos casos, problemas de alocação podem ser reduzidos pela subdivisão do sistema. Quando isto é possível, é um procedimento adequado se decisões baseadas nos resultados da ACV tem um efeito significante nas funções usadas internamente, porém um efeito pequeno no volume de produção de funções externas. Em outros casos, há um grande consumo de tempo e/ou não resulta em uma informação precisa e compreensiva sobre as consequências ambientais das ações. Este procedimento é adequado sob as condições citadas e na condição adicional que a alocação seja baseada nas relações físicas entre as cargas ambientais e as funções. Caso contrário, o procedimento de alocação não resultará em uma informação precisa, nem consistente, sobre as consequências ambientais das ações.

Evitar a alocação por meio da expansão do sistema nem sempre é possível para certos casos como co-produtos da produção de materiais renováveis, uma vez 
que as substituições de produtos envolvidas podem ser complexas, difíceis de determinar e, algumas vezes, podem envolver regressões infinitas (WEIDEMA, 1999).

Neste contexto, Weidema, Fress e Nielsen (1999) apresentam um procedimento para identificação dos processos afetados que pode ser adaptado para os problemas mais complexos. Com este procedimento, o autor afirma que a alocação pode (e deve) sempre ser evitada em ACV consequenciais.

A Figura 4 mostra o modelo proposto por Weidema, Fress e Nielsen (1999). Nela pode ser observado como o processo de co-produção tem um produto determinante, no caso o produto $A$, sendo este o produto que determina o volume de produção do processo. O produto determinante não é necessariamente o produto usado no estudo de ciclo de vida específico.

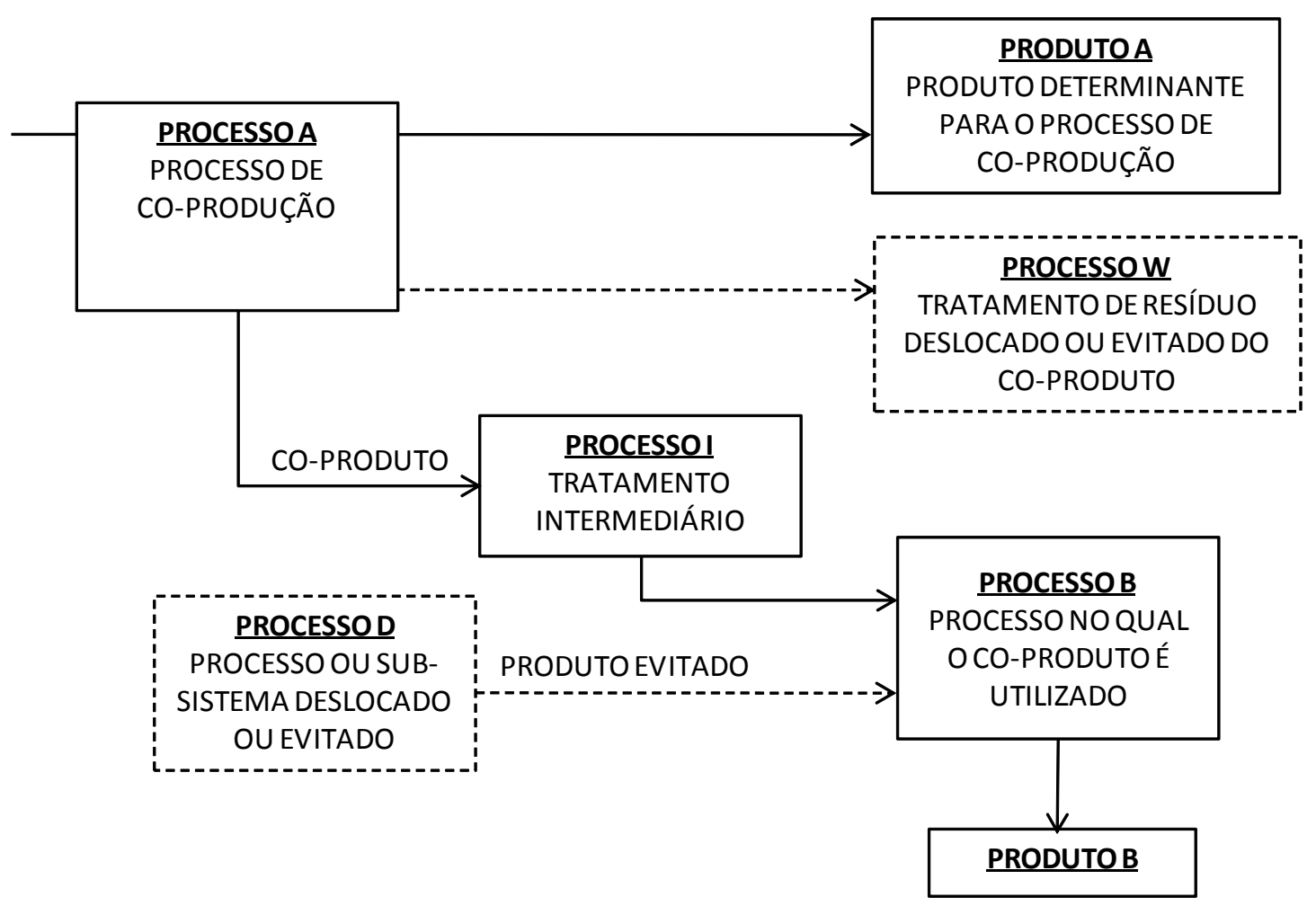

Figura 4 - Modelo para expansão do sistema e delimitação em relação ao co-produto (adaptado de WEIDEMA; FRESS; NIELSEN, 1999).

A Figura 4 mostra apenas um co-produto no modelo; entretanto, na prática pode haver mais de um co-produto, enquanto que em um determinado momento possa existir apenas um produto determinante. Dizer que um produto é determinante para o volume de produção de um processo é o mesmo que dizer que este processo 
será afetado pela mudança na demanda deste produto. Ademais, quando se diz que pode haver apenas um produto determinante em um determinado momento, não é o mesmo que dizer que os outros co-produtos não são importantes. Que os coprodutos possam obter um certo preço no mercado pode certamente ser uma condição para o processo expandir o seu volume de produção. Entretanto, quando esta pré-condição é preenchida, ainda é apenas uma mudança na demanda para o produto determinante que estará possibilitado a afetar o volume de produção do processo (WEIDEMA; FRESS; NIELSEN, 1999).

Realizar uma expansão do sistema em relação aos co-produtos é exatamente identificar como o volume de produção do processo na Figura 4 será afetado pela mudança na demanda do produto que é usado no estudo de ciclo de vida em questão (válidos os dois casos: quando for o produto determinante do processo de co-produção, produto $A$, ou quando for o produto no qual o co-produto é utilizado, produto B) (WEIDEMA; FRESS; NIELSEN, 1999).

\subsection{INFLUÊNCIA DO MERCADO}

$\mathrm{Na}$ aplicação da ACV consequencial, o mercado do qual o sistema de produto estudado faz parte tem influência tanto nos dados a serem usados no estudo como na delimitação do próprio sistema.

O estudo do mercado deve ser feito para identificar as tecnologias marginais que serão usadas na ACV consequencial e, assim, delimitar o sistema baseado no mercado. O efeito do mercado irá auxiliar no mapeamento dos produtos que poderão ser substituídos pelos co-produtos do sistema estudado.

\subsubsection{Estudo do mercado}

Segundo Ekvall e Andrae (2006), virtualmente todos os produtos intermediários em um ciclo de vida são tratados em um mercado. O equilíbrio entre o 
suprimento e a demanda neste mercado deve ser levado em consideração para descrever mais precisamente as consequências do uso de um produto específico, material, químico, ou energia motriz no ciclo de vida investigado. Entretanto, a coleta ou a geração incompleta de dados econômicos indicam que os modelos econômicos de equilíbrio parcial apenas podem ser desenvolvidos para alguns mercados, restringindo o seu uso. A decisão que considera quais mercados serão modelados em um inventário de ACV consequencial pode ser baseada em experiências anteriores dos avaliadores.

Para Weidema (2003), uma substituição de produto, ou seja, a escolha de um produto frente a outro, irá resultar em mudança na demanda e suprimento dos produtos intermediários que entram e saem do processo no qual a substituição ocorre. O autor define a substituição de produto como pequena ou marginal quando a mesma não afeta os parâmetros que determinam a situação do mercado global, ou seja, o sentido da tendência do volume de mercado e as suas restrições, e os custos de produção dos produtos e tecnologias envolvidos. As consequências da substituição podem então ser assumidas como linearmente relacionadas ao tamanho da substituição e tanto um aumento como uma diminuição do volume irá afetar os mesmos processos.

Weidema, Fress e Nielsen (1999) apresentam um procedimento de 5 (cinco) passos para identificação dos processos onde espera-se que sejam afetados por tais mudanças na demanda por um produto intermediário específico. A árvore de decisão deste procedimento é apresentada como Anexo A.

Muitas vezes a identificação da tecnologia marginal pode não ser tão trivial, requerendo que os avaliadores do estudo façam simplificações e assumam premissas para considerar uma tecnologia marginal. No caso de estudo de Ekvall e Andrae (2006), que compreendeu um comparativo entre soldas livres de chumbo utilizando a ACV atribucional e consequencial, os autores não tinham experiências relevantes para a escolha do mercado no início do projeto. Para isso, eles usaram o fato de que o fluxo de chumbo era o tema político acessível na época e decidiram focar nos mercados de chumbo e de sucata de chumbo. Outro exemplo relativo à dificuldade em determinar a tecnologia marginal é o citado por Dalgaard (2008). O produto substituto para o óleo de soja (co-produto do sistema estudado) foi definido para dois óleos: de palma; e de colza. No seu estudo, Dalgaard (2008) realizou duas 
ACVs, uma para cada óleo como produto marginal, pois as situações de mercado geralmente mudavam de um ano para outro.

Há casos ainda em que o uso de energia elétrica torna o mapeamento da tecnologia marginal mais complexo. Lund; Mathiesen e Christensen (2010) descrevem a complexidade em identificar um conjunto de tecnologias marginais para a eletricidade. Neste estudo, os autores concluem que as consequências ambientais das mudanças marginais no suprimento de eletricidade não podem ser sempre representadas unicamente pelas mudanças a longo prazo na capacidade da usina, conhecida como tecnologia marginal de longo prazo. A mudança marginal na capacidade terá que operar como parte integrante da energia total do sistema.

\subsubsection{Efeito do mercado}

A ACV atribucional é baseada na suposição implícita de que um aumento no uso de um produto no ciclo de vida investigado irá resultar em um aumento correspondente na produção daquele produto. Essa relação linear entre a demanda e a produção não é real para alguns casos de estudo, como por exemplo, processos multifuncionais (produção de um produto $A$ depende da demanda de um produto $B$ ) e produtos cuja quantidade produzida é constrita por alguma legislação ou restrições físicas (EKWALL; WEIDEMA, 2004).

Para Sandén e Karlström (2007), as consequências podem ser divididas em duas ordens. A primeira ordem de consequências é a das relações proporcionadas entre o uso, a produção e o manejo de resíduos de um produto e os impactos ambientais (por exemplo, liberações). Essas consequências são cadeias de causaefeito feitas pelo fluxo físico.

A segunda ordem de consequências é um tipo mais indireto de efeitos que leva em consideração os fluxos econômicos relacionados às correntes físicas que foram identificadas. Na literatura de ACV consequencial, tem sido observado que um aumento na demanda marginal não tem que necessariamente implicar que uma unidade adicional do bem demandado seja fornecida. Ao invés disso, uma diminuição na demanda para um fluxo de entrada, que é constrito, irá induzir a 
produção de um substituto. Como consequência, os dados marginais (a última unidade produzida) diferirão dos dados médios. Um aumento na produção pode também afetar a demanda pelo produto e produtos relacionados (SANDÉN; KARLSTRÖM, 2007).

Um aumento no uso de um produto no ciclo de vida investigado, é provável, contribui para um aumento no preço deste produto. Como resultado provável, pode haver uma redução no uso do produto em outros ciclos de vidas. Este efeito pode ser chamado de mecanismo de feedback negativo. A robustez do feedback negativo e, portanto, os efeitos de uma mudança dependem de quão sensíveis a demanda e a produção são em relação às mudanças no preço. Esta sensibilidade pode ser quantificada em termos de elasticidade de preço (EKWALL; WEIDEMA, 2004).

Por outro lado, o uso de um novo produto no ciclo de vida pode ajudar o produtor a estabelecer o produto no mercado, fazendo com que outras pessoas usem o produto. Estes são mecanismos de feedback positivo: como resultados destes mecanismos, o aumento no uso de um produto no ciclo de vida investigado pode resultar em um aumento no uso do produto em outros ciclos de vida (EKWALL; WEIDEMA, 2004).

Como exemplo de feedback positivo, tem-se o caso citado por Ekvall e Weidema (2004) que considera uma ACV do produto diamante. Os resíduos provenientes da mineração do diamante são inteiramente usados na construção de estradas. Um aumento na extração de diamantes resulta no aumento da quantidade de resíduos disponíveis para a construção de estradas.

Pode-se citar como exemplo de feedback negativo, o caso também citado por Ekvall e Weidema (2004) que considera uma ACV hipotética de uma tábua de aglomerado (chapa de madeira) fabricada a partir de serragem. A serragem pouco contribui para a receita total da serraria da qual ela é proveniente. A serragem que não é usada para a produção do aglomerado é vendida a um preço menor como combustível. Os autores explicam que é razoável assumir que os processos da serraria não são afetados pela demanda do produtor de aglomerado. Ao contrário, é provável que o efeito de aumento da produção de aglomerado diminua a venda da serragem como combustível e que outros combustíveis sejam usados em seu lugar. 
No trabalho de Sandén e Karlstöm (2007), os autores mostram como os diferentes efeitos do mercado mudam o ciclo de vida ${ }^{1}$ de uma tecnologia. Segundo os autores, é observado que a difusão de tecnologias (e muitos outros fenômenos) tendem a seguir uma curva do tipo "S", como ilustrado na Figura 5 . O ciclo de vida de uma tecnologia pode então ser dividido em diferentes fases.

Para uma tecnologia madura, que realizou grande parte de seu potencial de crescimento e aprendizagem, não há relevância do mecanismo de feedback positivo. Neste caso, mecanismos de feedback negativo, como por exemplo, efeitos devido aos ajustes de equilíbrio, podem ser mais importantes ${ }^{2}$. Para uma tecnologia emergente, que ainda está na fase de formação, o impacto ambiental direto é pequeno e o feedback negativo é inexistente ou pouco modifica o impacto total da tecnologia. Em vez disso, as principais consequências ambientais de um investimento provenientes do feedback positivo podem influenciar o padrão de crescimento, tendendo a um potencial futuro. Os autores afirmam que esta simples subdivisão poderia funcionar como regra geral sobre onde focar as avaliações ambientais de investimentos, tais como uma ACV consequencial de tecnologia.

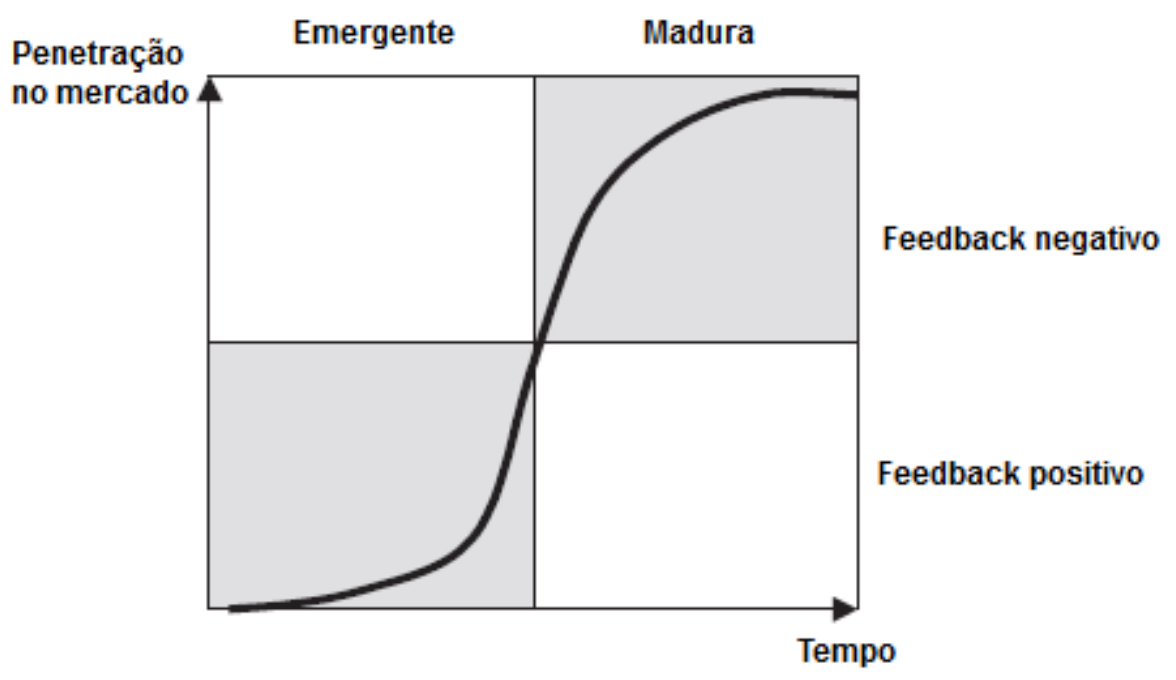

Figura 5 - Importância dos mecanismos de feedback positivo e negativo nas diferentes fases da tecnologia (SANDÉN; KARLSTRÖM, 2007).

\footnotetext{
${ }^{1}$ Este "ciclo de vida" não deve ser confundido com o ciclo de vida do berço ao túmulo de um objeto que é referenciado no conceito de "avaliação do ciclo de vida" (SANDÉNं; KARLSTRÖM, 2007).

2 Uma tecnologia madura pode, entretanto, começar a se difundir em novos mercados e, assim, começar a escalar uma nova curva do tipo "S". Então, o feedback positivo pode ser importante (SANDÉN; KARLSTRÖM, 2007).
} 
Outra abordagem também pode ser feita em termos lucro, com a análise de efeitos ricochetes (ou efeito rebote, rebound effects). Os efeitos ricochetes diretos lidam com o fato de que melhorias na eficiência da produção geralmente levam a reduções de custo que fornecem a possibilidade de maior compra do produto melhorado ou outros produtos e serviços. Os efeitos ricochetes indiretos são relacionados aos impactos de nível "macro" ou efeitos na produção ao invés de hábitos de consumo individual (THIESEN et al., 2008).

Em Thiesen et al., (2008), os autores citam como exemplo para ilustrar esses efeitos, a comparação entre as lâmpadas economizadoras de energia e as lâmpadas convencionais. Para os autores, mesmo as tecnologias mais promissoras em relação à economia de energia, como lâmpadas economizadoras de energia, também possuem um lado negativo. O custo total dessas lâmpadas, considerando todo o seu ciclo de vida, é consideravelmente menor comparado às lâmpadas convencionais, fazendo com que o consumidor possua um poder de compra adicional devido a esta diferença que deixa de pagar. É provável que este dinheiro seja gasto em outros produtos, os quais possuem impactos ambientais que também devem ser contabilizados. Em uma ACV comparativa entre esses dois tipos de lâmpadas, por exemplo, pode-se argumentar que os impactos ambientais relacionados a este consumo adicional devem ser acrescidos aos impactos das lâmpadas economizadoras de energia, considerando os chamados efeitos ricochetes. Os impactos ambientais desse consumo adicional podem ser denominados como um efeito ricochete causado pela escolha da alternativa mais barata.

Para Ekwall e Weidema (2004), um estudo conjunto entre economistas e engenheiros deve ser requerido para modelar os efeitos gerais do mercado. Uma vez que valores de elasticidade de preços, entre outras variáveis, podem ser difíceis de obter, simplificações também podem ser requeridas para fazer o inventário de uma ACV consequencial aplicável.

Dentro dos estudos interdisciplinares, recomenda-se também o estudo conjunto entre economistas e estatísticos para modelar os futuros cenários onde os produtos estudados na ACV terão lugar nestas projeções.

De acordo com Wright (2004), a estrutura industrial está em constante modificação, e as empresas, dentro de cada uma das indústrias, enfrentam incertezas quanto ao rumo que estas mudanças podem tomar. A partir desta 
percepção, muitos métodos têm sido desenvolvidos por pesquisadores e empresas para lidar com estas incertezas.

O autor ressalta a velocidade surpreendente das mudanças nas organizações, que afetam a escala e o escopo da tomada de decisão gerencial, destacando o fato de, em geral, os gerentes basearem suas decisões em modelos mentais, fruto de experiências anteriores, que não são muito eficientes em indústrias instáveis, pois pode negligenciar variáveis importantes. É neste momento que surge a necessidade de uma abordagem mais explícita da incerteza, as empresas começam a trabalhar com cenários. Um das definições de cenários descritas pelo autor é o conjunto formado pela descrição de uma situação futura e do encaminhamento dos acontecimentos que permitam passar da situação de origem à situação futura.

O surgimento da análise de cenários permitiu uma abordagem mais completa das incertezas que afetam o ambiente industrial e muitas empresas estão adotando esta técnica no planejamento estratégico (WRIGHT, 2004).

O método de cenário, bem como outros para a previsão de dados, são abordados na seção 4.8 .

\subsubsection{Modelagem econômica}

Inicialmente, nos estudos de ACV consequencial foram utilizados modelos econômicos mais simples, como modelagem de equilíbrio parcial e abordagem heurística. Com o desenvolvimento desta ferramenta, modelos econômicos mais complexos foram adicionados aos cálculos, tais como modelagem CGE (equilíbrio geral computável) e MMMR-PE (equilíbrio parcial multi-regional e multi-mercado) (EARLES; HALOG, 2011).

Em 2000, Bouman et al. começaram a investigar as similaridades e diferenças entre ACV e técnicas econômicas chamadas de modelagem de equilíbrio parcial ( $P E$ modelling). Modelos de equilíbrio parcial são tipicamente usados para analisar os possíveis efeitos da política em um mercado ou em um conjunto de mercados. Métodos de equilíbrio parcial permitem a investigação de bens 
substituíveis, pois os mesmo estão relacionados à mudança no preço. Estes métodos podem ser simplificados, ou modelos mais complexos que incorporam centenas de bens através de setores múltiplos (EARLES; HALOG, 2011).

Bouman et al. (2000) apresentam os modelos de equilíbrio parcial como sendo o resultado de um mercado ou um conjunto de mercados que descreve as relações comportamentais que compõem este resultado. Isto significa que o impacto de uma mudança na política ambiental, por exemplo, pode ser rastreado até os seus efeitos no consumo e nas decisões de produção. Uma vez que as regras de decisão são explicitamente modeladas, os efeitos de preço e os efeitos da substituição de uma dada política podem ser analisados.

Para Bouman et al. (2000), as vantagens e desvantagens dos modelos de equilíbrio parcial podem ser resumidas da seguinte forma: (i) modelos econômicos de equilíbrio parcial descrevem o impacto dos preços sobre o comportamento econômico, o qual permite a análise da política ambiental baseada no preço. (ii) Estes modelos econômicos podem revelar a complexidade das relações econômicas e a interdependência dos agentes econômicos. Estes são os fatores que determinam os efeitos da política de uma forma que é difícil prever sem tal modelo. (iii) Para este tipo de modelagem, uma grande quantidade de informação é requerida para formular um modelo que retrate os mecanismos do mundo real de maneira satisfatória. Não apenas o usuário necessita estimar os parâmetros do modelo, é também necessário avaliar a forma funcional das relações. Isto representa inserir severas restrições no tamanho do sistema. (iv) A necessidade de manter o modelo matematicamente tratável é uma restrição importante para a forma funcional das equações do modelo, muitas vezes necessitando-se fazer suposições implausíveis.

Utilizando os conceitos de microeconomia da elasticidade de preço do suprimento e demanda, Ekvall (2000) desenvolveu uma técnica quantitativa para estimar impactos indiretos quando feita a ACV usando um modelo simples de equilíbrio parcial para dois bens. De acordo com Earles e Halog (2011), o termo impacto indireto foi introduzido por Ekvall (2000) para denotar as consequências ambientais não compreendidas na cadeia de suprimentos físicos, as quais são resultados de forças do mercado (por exemplo, substituição de produto). Ekvall (2000) usou o contexto da reciclagem de ciclo aberto para demonstrar como a elasticidade do suprimento e demanda podem caracterizar estudos de ACV consequencial. 
Os tipos maiores de modelos de equilíbrio parcial que englobam várias regiões de mercado e centenas de dados de agricultura e commodities (produtos de base), por exemplo, podem ser categorizados como modelos de equilíbrio parcial multi-regional e multi-mercado (MMMR-PE: Multi-Market, Multi-Region Partial Equilibrium Models). Os modelos de MMMR-PE existentes também têm sido utilizados para estimar os impactos de ciclo de vida da mudança indireta do uso do solo (ILUC - Indirect Land-Use Change).

Searchinger et al. (2008) estudaram os impactos do ILUC resultantes do aumento da demanda adicional por biocombustível de terra dedicada à produção de milho. Os autores explicam que este aumento de demanda pode resultar no uso de florestas ou pradarias para lavouras liberando a longo prazo o carbono armazenado no solo. Como alternativa, os agricultores podem desviar culturas existentes ou terras agrícolas à produção de biocombustíveis. Como resultado, os preços do cultivo sobem, levando à conversão de terra internacionalmente para atender a demanda adicional.

Já os modelos de equilíbrio geral computáveis (CGE - Computable General Equilibrium) promovem outro método para estimar os impactos indiretos na ACV. Similares aos modelos de equilíbrio parcial, os modelos de equilíbrio geral computáveis geralmente são usados para modelar os efeitos da política por meio da suposição de maximização dos agentes econômicos. Ao contrário dos modelos de equilíbrio parcial, os modelos CGE incluem todos os setores dentro do sistema econômico. Enquanto os modelos CGE são mais abrangentes que os modelos de equilíbrio parcial, eles normalmente não possuem a quantidade de detalhes de nível setorial (EKVALL, 2002).

Para Thissen apud Pedott (2008), o essencial no equilíbrio geral macroeconômico são os enlaces entre as rendas de vários grupos de uma sociedade, o padrão da demanda, o balanço de pagamentos e a estrutura de produção multisetorial. Tal modelagem incorpora um grupo de equações comportamentais que descrevem o padrão de interação econômica entre os agentes identificados no modelo, dado suas restrições tecnológicas e institucionais.

Dentre as áreas mais privilegiadas para aplicação de modelos de CGE estão questões que demandam, ao mesmo tempo, análises globais e desagregadas. Desta forma, pode-se apontar as políticas comerciais, políticas fiscais, avaliação de estratégias de desenvolvimento, análises do crescimento econômico, mudanças 
estruturais e distribuição de renda, entre outras. Normalmente, tal abordagem pode ser utilizada quando os pesquisadores necessitam obter resultados sobre os impactos de determinada política econômica sobre um país ou uma região (PEDOTT, 2008).

Pedoott (2008) distingue algumas características dos modelos de CGE: (i) estes modelos dão uma completa explicação do fluxo circular da renda na economia, supondo-a em equilíbrio, e fazendo uso de uma Matriz de Contabilidade Social ${ }^{3}$. (ii) modelos de CGE constroem representações bastante claras a respeito do comportamento dos setores, instituições e das famílias dentro de uma estrutura econômica, e o modo como os padrões de produção, distribuição e consumo se ajustam às mudanças, tais como, por exemplo, choques de preços externos.

O motivo pelo qual os modelos de CGE tornaram-se muito populares nos últimos anos, resultou de sua possibilidade de modelagem que contempla uma complexa interdependência entre as instituições e os agentes de uma economia. Os avanços da informática e das técnicas de resolução numérica de sistemas de equações também contribuíram para que a utilização de modelos de CGE se tornasse mais usual. No entanto, algumas dificuldades na elaboração desses modelos ainda persistem. Como, por exemplo, a falta de disponibilidade de informações necessárias para a calibragem de seus parâmetros, ou ainda para outros casos, quando fontes de informações existentes estão defasadas e incompatíveis entre si, o que requer um processo de ajustamento para a obtenção da consistência necessária. Também existe a dificuldade, por parte do pesquisador, em modelar o real comportamento dos agentes econômicos adequadamente. Podendo haver suposições equivocadas quanto às preferências, tecnologia e regras comportamentais (FOCHEZATTO, 1999 apud PEDOTT, 2008).

Os modelos de CGE oferecem algumas vantagens sobre os demais tipos de modelos, pois permitem realizar simulações de políticas macroeconômicas. Quando são apropriadamente preparados. Tais modelos adaptam-se bem às realidades de cada país e à disponibilidade de dados nacionais confiáveis. Também podem efetuar análises de diferentes setores, como o mercado de trabalho, sistema financeiro e o mercado de crédito com objetivo de aprofundar os estudos sobre as fontes de

\footnotetext{
${ }^{3}$ Através da Matriz de Contabilidade Social, que apresenta uma base de dados empírica sobre a economia em estudo, os modelos de CGE atribuem formas funcionais que, supostamente, representam as ações comportamentais dos agentes econômicos especificados em tais modelos (RODRIGUES, 2007 apud PEDOTT, 2008).
} 
crescimento econômico. Os modelos de CGE têm sido utilizados tanto para países desenvolvidos quanto para países em desenvolvimento com o objetivo de projetar cenários possíveis dado às tendências econômicas nacionais e internacionais. $O$ que caracteriza a possibilidade de utilização de um instrumento de planejamento estratégico em relação às tomadas de decisão para aplicação de determinadas políticas econômicas (PEDOTT, 2008).

Para Ekvall e Weidema (2004), as relações econômicas casuais são pelo menos tão importantes quanto os fluxos físicos. Os efeitos de uma decisão dependem no quão sensível a produção e a demanda de produtos afetados podem modificar o preço do produto. Eles também dependem da facilidade do produto afetado poder ser substituído por outros produtos e dos prováveis produtos substitutos. Tais aspectos são incluídos em modelos econômicos de equilíbrio parcial (BOUMAN et al., 2000). Assim, a solução pode ser a integração de modelos de equilíbrio parcial no inventário de ciclo de vida, ICV. Bouman et al. (2000) afirmam que os diferentes tipos de modelos geram tipos de informação diferentes e complementares. Os autores sugerem que a integração de diferentes ferramentas implica em um risco que as vantagens específicas das diferentes ferramentas são perdidas. Entretanto, neste caso, a integração das ferramentas - ICV e análise de equilíbrio parcial - resultariam em uma nova ferramenta com vantagens específicas no que diz respeito à modelagem das consequências de mudanças.

De acordo com Bouman et al. (2000), as diversas estratégias de modelos empregados por pesquisadores que estudam interações entre fluxos de matérias e economia são diferentes em muitos aspectos. As diferenças técnicas são as mais visíveis, tais como métodos matemáticos, requerimento de dados e demarcação do problema. Mais sutil, mas possivelmente mais importante, são diferenças básicas nas premissas e objetivos. Premissas relacionadas à função dos materiais na economia, à inflexibilidade das relações econômicas, à robustez das restrições físicas, e à maneira que economia e ambiente se interagem podem diferenciar consideravelmente. Muitas destas diferenças não são em um primeiro momento determinadas pela natureza do problema estudado, mas podem frequentemente ser rastreadas pelo fato da ciência ambiental ser um campo interdisciplinar.

Em um estudo de ACV consequencial, vários modelos econômicos podem ser escolhidos de acordo com os parâmetros que o analista de ACV tenha em mãos. Earles e Halog (2011) apresentam um resumo interessante sobre as aplicações dos 
modelos econômicos em diferentes estudos de ACV. Este resumo é apresentado no Anexo C.

\subsection{PREVISÃO DE DADOS}

Em muitas aplicações, é relevante a modelagem de sistemas futuros. Este pode ser o caso, por exemplo, da aplicação da ACV consequencial onde os impactos de uma decisão possível futura são avaliados, ou da aplicação de uma ACV atribucional que tenha o objeto de avaliar tecnologias ou sistemas futuros. Sempre que os sistemas estudados tratam-se de sistemas futuros, uma decisão deve ser tomada quanto a forma como este cenário futuro será modelado. Um caminho simples é assumir que o futuro é como o presente e então modelar o sistema presente. Algumas vezes esta pode ser uma boa suposição. Em outros casos pode ser adequado elaborar outros cenários futuros (FINNVEDEN et al., 2009).

O foco básico da ACV consequencial é estudar as consequências ambientais de possíveis mudanças quando se altera o sistema do produto (substituição de produto, alteração na demanda). Para isso, devem ser estudados diferentes métodos para fazer essas previsões (a curto, médio e longo prazo) e analisar qual a consequência no futuro de uma decisão tomada hoje.

Segundo Weidema (2003), os processos a serem incluídos nos sistemas de produtos estudados podem sofrer variações ao longo do tempo, dependendo das situações do mercado futuro. Sendo assim, na aplicação de um estudo de ACV consequencial é relevante prever: as condições futuras do mercado determinando quais as substituições de produto futuras terão lugar; as condições geográficas e tecnológicas dos processos futuros e as trocas ambientais futuras desses processos.

Finnveden et al. (2009) está de acordo com Weidema (2003) quando diz que uma alternativa para a previsão, elaboração de cenários futuros, seria o uso de suposições injustificadas acerca do futuro, ou o uso de dados de uma situação presente como base para os dados de uma situação futura. Entretanto, para Weidema (2003), enquanto esta alternativa pode ser adequada em algumas 
situações (especialmente na primeira iteração de uma avaliação de ciclo de vida) e para algumas partes do sistema de produto, o uso da previsão de dados é geralmente necessário para assegurar uma validade adequada dos dados usados e das conclusões feitas.

Weidema (2003) propõem um procedimento baseado em cinco passos para melhorar a consistência e transparência das previsões. São eles:

1) Determinar as partes do sistema de produto nas quais serão feitas as previsões;

2) Determinar os detalhes necessários para as previsões;

3) Escolher os métodos de previsão relevantes;

4) Realizar a previsão;

5) Analisar a consistência.

Diferentes técnicas podem ser usadas para desenvolver diferentes tipos de cenários incluindo modelagem de séries temporais e modelagens de otimização resultando tanto em cenários quantitativos como qualitativos (FINNVEDEN et al., 2009). Métodos quantitativos são baseados na caracterização da estrutura de séries temporais históricas e na previsão de eventos futuros baseada naquela estrutura. Métodos qualitativos envolvem estimações subjetivas através da opinião de especialistas ou consumidores. Apesar dos métodos qualitativos compreenderem técnicas estruturadas, como, por exemplo, Pesquisas de Intenções e Delphi, o processo para obter a previsão é subjetivo (LEMOS, 2006).

Para realizar o passo 3 de seu procedimento, Weidema (2003) separou essas técnicas em 6 grupos:

- Métodos de extrapolação;

- Métodos de modelagem;

- Métodos participativos;

- Métodos exploratórios;

- Métodos normativos;

- Métodos de cenário. 
O método de extrapolação é baseado na extensão histórica e tendências atuais ao futuro. É baseada na premissa de que o futuro representa uma extensão lógica do passado e que a informação contida em dados históricos pode ser extraída, analisada, e reduzida a uma ou mais equações, podendo ser usada para prever eventos futuros (WEIDEMA, 2003).

O método de modelagem busca identificar os mecanismos determinantes e modelar como os efeitos combinados de diversos mecanismos podem influenciar o futuro. É baseada na premissa de que os eventos futuros serão influenciados por mecanismos análogos àqueles determinantes em eventos passados. Assim, a melhor maneira de se descrever o futuro é pela identificação dos mecanismos determinantes e modelar como estes irão influenciar o futuro (WEIDEMA, 2003).

Os métodos participativos buscam o conhecimento e a opinião de especialistas e das partes interessadas ("stakeholders"). São baseados na premissa de que o futuro é formado pela mistura complexa de tendências, eventos randômicos e ações de indivíduos e instituições. Desta maneira, para realizar a previsão de futuro, o conhecimento e as opiniões de especialistas e "stakeholders" são mais úteis que os métodos racionais. Os resultados destes métodos são geralmente mais normativos (o que o futuro deve ser) que analíticos (o que o futuro provavelmente é) (WEIDEMA, 2003).

Os métodos exploratórios procuram estruturar todos os futuros possíveis combinando técnicas analíticas, as quais fornecem uma descrição qualitativa exaustiva do campo, com técnicas imaginativas focadas no preenchimento de todas as lacunas na estrutura analítica (WEIDEMA, 2003).

Os métodos normativos começam em estabelecendo o futuro desejado e então seguem com passos retroativos no tempo para identificar os passos necessários para alcançar este objetivo (WEIDEMA, 2003).

O método de cenário inclui e combina aspectos de outros métodos, especialmente participativos, modelagem e métodos exploratórios, com o objetivo de criar diversos cenários futuros distintos. São baseados na premissa de que o futuro é essencialmente imprevisível e amplamente aleatório (WEIDEMA, 2003).

Estão expostas na Tabela 1 as diferentes técnicas que podem ser usadas em cada método e as suas limitações. No Anexo B também é apresentado um exemplo de guia para auxiliar na escolha do método de previsão. 
Tabela 1 - Técnicas para métodos de previsão de dados e as suas limitações.

\begin{tabular}{|c|c|c|}
\hline Método & Técnicas & Limitações \\
\hline Extrapolação & $\begin{array}{l}\text { Análise de tendência } \\
\text { Séries temporais } \\
\text { Econometria }\end{array}$ & $\begin{array}{l}\text { Não inclui efeitos combinados de diversos desenvolvimentos. } \\
\text { Requer dados históricos consistentes e coletados ao longo de um } \\
\text { período razoável de tempo. } \\
\text { Não recomendável para projecões a longo prazo. }\end{array}$ \\
\hline Modelagem & $\begin{array}{l}\text { Análise de impacto cruzado, } \\
\text { Sistemas dinâmicos probabilísticos } \\
\text { Modelos de equilíbrio }\end{array}$ & $\begin{array}{l}\text { Como este modelo combina efeitos de diversos desenvolvimentos, } \\
\text { dependendo do número de variáveis e o grau de incerteza inserido } \\
\text { no modelo, pode resultar em uma simplificação do cenário futuro. } \\
\text { Desta maneira, em estudos que lidam com processos menos } \\
\text { previsíveis e sistemas mais complexos, o uso deste método deve ser } \\
\text { combinado com outro. }\end{array}$ \\
\hline Participativos & $\begin{array}{c}\text { Técnica Delphi } \\
\text { Painéis de especialistas }\end{array}$ & $\begin{array}{l}\text { Dificuldade na identificação de especialistas. As projeções podem ser } \\
\text { feitas de maneira incorreta ou preconceituosa, estando sujeitas à } \\
\text { subjetividade. } \\
\text { Projeções podem ser ambíguas e divergentes entre especialistas da } \\
\text { mesma área. }\end{array}$ \\
\hline Exploratórios & $\begin{array}{l}\text { Análise morfológica } \\
\text { Árvores de relevância }\end{array}$ & \multirow{2}{*}{$\begin{array}{l}\text { Apenas relevantes para os processos onde os tomadores de decisão } \\
\text { tenham grande influência sobre os mesmos para que, desta maneira, } \\
\text { os passos necessários para se chegar ao objetivo da previsão sejam } \\
\text { alcançados. } \\
\text { Podem levar a inúmeras possibilidades, o que dificulta a identificação } \\
\text { de quais possibilidades são as mais relevantes. }\end{array}$} \\
\hline Normativos & Backcasting & \\
\hline Cenário & $\begin{array}{l}\text { (técnicas citadas em outros métodos, } \\
\text { dependendo da combinação) }\end{array}$ & $\begin{array}{l}\text { Podem levar a uma sofisticação de uso desnecessária quando } \\
\text { aplicados a previsões de médio e longo prazo. }\end{array}$ \\
\hline
\end{tabular}


Todos os diferentes tipos de métodos podem ser de interesse quando combinados com os estudos de ACV. Se o horizonte temporal for de longo prazo (de 5 a 25 anos), e a incerteza das previsões é relevante, podem ser usados métodos exploratórios que descrevem possíveis desenvolvimentos futuros de sistemas de energia, por exemplo. Muitos estudos de sistemas de gerenciamento de resíduos têm, por exemplo, incluído métodos exploratórios para os combustíveis que estão competindo com resíduos sólidos como combustíveis, um aspecto que pode ser decisivo para os resultados de uma ACV de gerenciamento de resíduos. Métodos exploratórios também têm sido usados, por exemplo, em estudos de energia e transporte. Métodos normativos podem ser usados em estudos de ACV como cenários exploratórios descrevendo o que pode acontecer. Entretanto, também pode ser interessante usar a ACV em estudos de cenários normativos para, por exemplo, avaliar impactos ambientais em diferentes cenários passados (FINNVEDEN et al, 2009).

A Tabela 2 apresenta um resumo dos diferentes tipos de processos que são estudados em uma avaliação de ciclo de vida, e sua correspondência com as diferentes ferramentas de previsão de dados a serem aplicadas.

Tabela 2 - Relevância dos métodos de previsão e sua dependência com o horizonte temporal e complexidade.

\begin{tabular}{c|c|c}
\hline \multirow{2}{*}{$\begin{array}{c}\text { HORIZONTE } \\
\text { TEMPORAL }\end{array}$} & $\begin{array}{c}\text { TIPO DE PROCESSO } \\
\text { quando nenhuma mudança brusca é } \\
\text { esperada, ou em que os } \\
\text { desenvolvimentos estão sob controle de } \\
\text { um tomador de decisões }\end{array}$ & $\begin{array}{c}\text { Previsões para processos } \\
\text { menos previsíveis ou de } \\
\text { maior complexidade }\end{array}$ \\
\hline \hline Longo prazo & $\begin{array}{c}\text { Métodos de modelagem, exploratórios e } \\
\text { normativos }\end{array}$ & Métodos de cenário \\
(de 5 a 25 anos) & Métodos de extrapolação & Métodos de modelagem e \\
(de 1 a 5 anos)
\end{tabular}

Fonte: adaptado de WEIDEMA, 2003. 
As divisões propostas na Tabela 2 devem servir apenas como guia para escolha dos métodos de previsão. Na prática, a distinção entre as diferentes situações e métodos relevantes não é exata e mais de um método pode ser relevante em uma situação específica. Geralmente, diferentes métodos podem ser combinados para resultar em uma previsão mais confiável (WEIDEMA, 2003).

De acordo com Lemos (2006), os quatro maiores problemas associados com o uso de previsões no apoio à tomada de decisões são: (i) a incerteza sobre o futuro, a qual está conectada ao grau de precisão da previsão, (ii) a escolha do método aplicado para gerar a previsão, (iii) a qualidade e confiabilidade do conjunto de dados de entrada do método; e (iv) a interpretação correta da previsão, ou seja, a maneira como serão utilizadas as previsões na tomada de decisão. Deve-se sempre ter em mente que a incerteza não pode ser eliminada, e consequentemente, o futuro pode sempre mudar e ser diferente do previsto. 


\section{RESULTADOS E DISCUSSÕES}

Para a seleção dos critérios que serão utilizados como parâmetros para a análise dos dois enfoques, atribucional e consequencial, da ACV, foram baseados nos critérios apresentados por Weidema (2011)

Para seleção desses critérios, foram considerados dois tipos de abordagens:

a) Critérios onde os dois enfoques se diferenciam no seu desenvolvimento;

b) Critérios que não influenciam na dinâmica do desenvolvimento dos enfoques, porém podem ser considerados na escolha entre um deles.

Em relação aos critérios onde os dois enfoques se diferenciam no seu desenvolvimento, foram selecionados: (i) fronteira do sistema; (ii) escolha dos dados e (iii) alocação e expansão do sistema.

Em relação aos critérios onde não há influência na dinâmica do desenvolvimento dos enfoques, foram selecionados: (i) custo; (ii) acurácia e precisão; (iii) simplicidade de execução e (iv) estabilidade no tempo.

As seções 5.1 a 5.7 são dedicadas às justificativas na escolha de cada critério e a discussão dos mesmos quando relacionados às ACV atribucional e consequencial.

\subsection{CRITÉRIO: FRONTEIRA DO SISTEMA}

Com a inserção da modelagem econômica no cálculo de uma avaliação de ciclo de vida, essa nova etapa permite à ACV consequencial analisar as variações da carga ambiental decorrentes do uso do produto em estudo, diferindo assim do cálculo feito pela ACV atribucional.

Para o enfoque atribucional, o cálculo do ciclo de vida é individualizado por sistemas, não há interação entre diferentes ciclos.

Pode-se dizer desta maneira, e de um modo simplista, que para a ACV atribucional as fronteiras consideradas no estudo são estáticas e para a ACV 
consequencial as fronteiras são dinâmicas, variando em função dos produtos marginais.

Atualmente, há discordância entre autores sobre a melhor representação da realidade do sistema de produto estudado. Autores, como União Europeia (2010), defendem que na ACV atribucional, o sistema reflete a realidade física existente em uma cadeia de suprimento. Outros autores, como Weidema (2004) e Guinée et al. (2001) apud Finnveden (2009), defendem que há somente um sistema de produto: o planeta; e todas as atividades estão interligadas, sofrendo e causando influência umas nas outras.

A definição da fronteira do sistema faz parte de uma das etapas importantes da ACV que é a definição do objetivo e escopo. Por ainda se ter diferentes opiniões sobre essa definição, este tema foi escolhido como um dos critérios para analisar os enfoques consequencial e atribucional.

Com a definição da fronteira de maneira estática, o cálculo pode se tornar mais simples. O processo a ser estudado se torna individualizado e a avaliação do ciclo de vida deste produto é feita de forma direta, sem sofrer interferência de sistemas vizinhos. Neste caso, tem-se a vantagem de ter um estudo simples, com as correntes e dados pertencentes ao sistema bem definidos. A desvantagem para a escolha da fronteira estática é o enrijecimento do modelo, servindo apenas para um estudo direcionado, sem considerar a influência do uso do produto em estudo com os sistemas adjacentes.

Com a definição da fronteira de maneira dinâmica, o cálculo pode se tornar mais completo, pois irá considerar os sistemas marginais que sofrerão influência do uso do produto em estudo. Dependendo do produto, essa fronteira pode sofrer alterações de acordo com os dados inseridos no modelo econômico que definiu essa fronteira, tais como, regionalização, horizonte temporal, etc. Neste caso, tem-se a vantagem de ter um sistema flexível que pode ser aferido ao longo do tempo, conforme as variações da modelagem econômica. A desvantagem para a escolha da fronteira dinâmica é a complexidade em que o estudo pode chegar dependendo das escolhas para a modelagem econômica. Além do mais, os estudos de mercado deverão ser sempre dependentes de profissionais da disciplina de Economia, cujos embasamentos teóricos podem divergir mesmo com profissionais da mesma área, alterando o resultado final do estudo de ACV. 


\subsection{CRITÉRIO: ESCOLHA DOS DADOS}

No estudo de ACV atribucional, não são incluídos os dados marginais, sendo somente usados dados médios refletindo as correntes físicas, ou dados específicos de um sistema de produto. No estudo de ACV consequencial, onde é aplicado o propósito de avaliar as consequências, com a inclusão das atividades que contribuem para as consequências ambientais de uma mudança, dados marginais são incluídos no cálculo (EKVALL; TILLMAN; MOLANDER, 2005).

A escolha dos dados faz parte de uma das importantes etapas da ACV que é a fase de inventário. A escolha da base de dados a ser utilizada e a confiabilidade na fonte desses dados é de suma importância para a validação do estudo. O tipo de dados, a quantidade e a qualidade dos mesmos interfere diretamente nos resultados de um estudo de ACV. Por essa relevância, este tema foi escolhido como um dos critérios para analisar os enfoques consequencial e atribucional.

$\mathrm{Na}$ escolha de dados usados na ACV consequencial, há a relação desses dados com magnitude da mudança. $O$ estabelecimento da magnitude da mudança deve ser feito de maneira cautelosa ao se analisar a tecnologia marginal afetada pelo produto em estudo. A vantagem do uso de dados marginais no estudo de ACV consequencial seria a visualização da mudança marginal quando feita a escolha do uso do produto em estudo. Adicionando estes dados, o mentor do estudo de ACV consequencial poderá contabilizar os impactos ambientais do sistema de estudo como um todo: do próprio produto em estudo e dos produtos que serão imediatamente afetados pelo seu uso. A desvantagem da escolha em usar estes dados é que se não for estabelecida uma boa base de premissas para a definição dos produtos marginais, algum dado marginal pode ser desconsiderado no cálculo ou até mesmo adicionado inadvertidamente. A base de premissas para identificação das tecnologias marginais deve seguir o procedimento escolhido para esta identificação, como por exemplo, o procedimento proposto por Weidema, Fress e Nielsen (1999).

Para os dados escolhidos em um estudo de ACV atribucional, a vantagem é a disponibilidade cada vez maior de dados médios disponíveis na literatura e em bancos de dados. No registro destes dados, a qualidade da coleta de dados primários de sistemas específicos garante a qualidade final da sua média, ou seja, 
garante a qualidade dos dados médios. A desvantagem da escolha de dados médios é a inclusão de tecnologias que possam ser restritivas ao estudo, que não refletem a realidade do sistema de produto em questão. Somando-se as diferenças dessas inclusões, estas podem interferir de maneira significativa o resultado final do estudo. Para avaliar as implicações destas inclusões de dados, há mecanismos para ao menos saber a magnitude dessa propagação e, a partir daí, fazer uso de técnicas para redução desses impactos. Recomenda-se, sempre que possível, a realização de análises de sensibilidade e incerteza nos estudos de ACV.

No caso do uso de dados específicos de um determinado sistema em estudo e na coleta de dados primários, não haveria diferença entre os dois enfoques, exceto pelo fato que para a ACV consequencial, a coleta dos dados primários seria maior, pois envolveria também o(s) sistema(s) incluído(s) pela expansão do sistema.

\subsection{CRITÉRIO: ALOCAÇÃO E EXPANSÃO DO SISTEMA}

A alocação do sistema é um dos gargalos no cálculo da ACV atribucional pelos seus métodos de definição não serem objetivos, e por isso, poderem ocasionar uma discrepância na divisão das cargas ambientais entre os co-produtos.

O problema da alocação ocorre quando em um processo multifuncional utiliza-se de uma ou mais funções para o ciclo de vida do produto em estudo, e uma diferente função (ou conjunto de funções) para os outros produtos, desde que esses não se separem fisicamente. Ou também devido ao fato que as funções geradas no ciclo de vida no produto em estudo são utilizadas em outro (RAMIREZ, 2009).

Pelo fato deste tema ainda ser considerado bastante polêmico e atualmente muito debatido na comunidade científica internacional, a alocação foi escolhida como critério para análise entre os enfoques atribucional e consequencial da ACV.

A Figura 6 ilustra simplificadamente a diferença em estudos onde há a alocação e o estudo onde é aplicada a expansão do sistema. 
ACV DO PRODUTO DE INTERESSE (A)

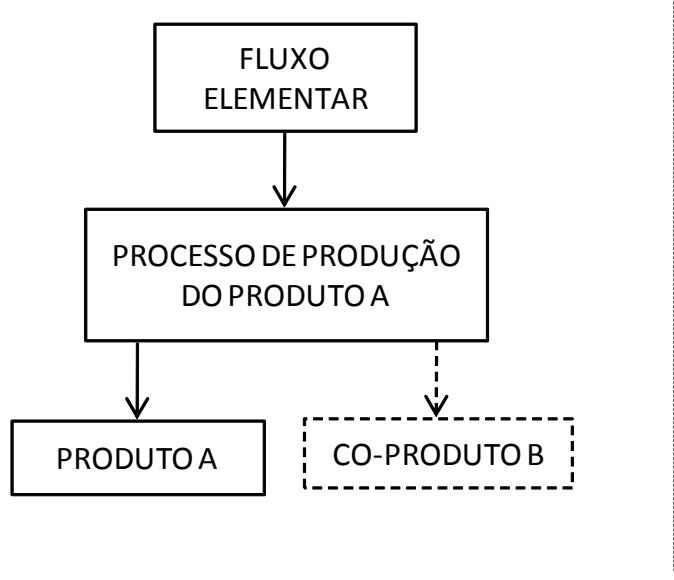

ACV DO PRODUTO C

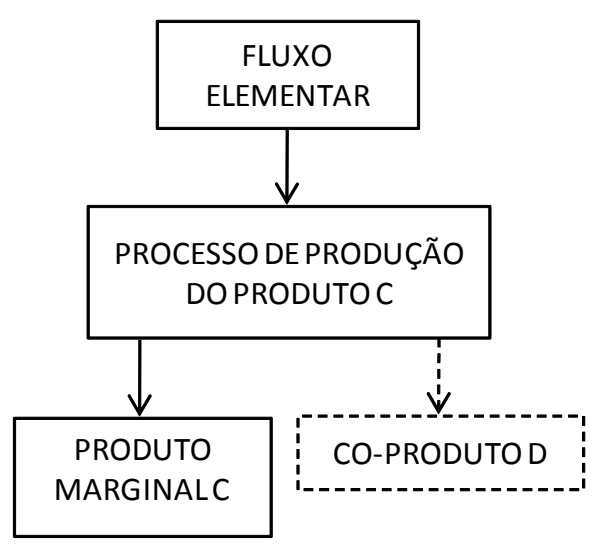

6a) ACV dos produtos A e C com alocação.

ACV DO PRODUTO DE INTERESSE (A)

ACV DO PRODUTO MARGINAL (C)
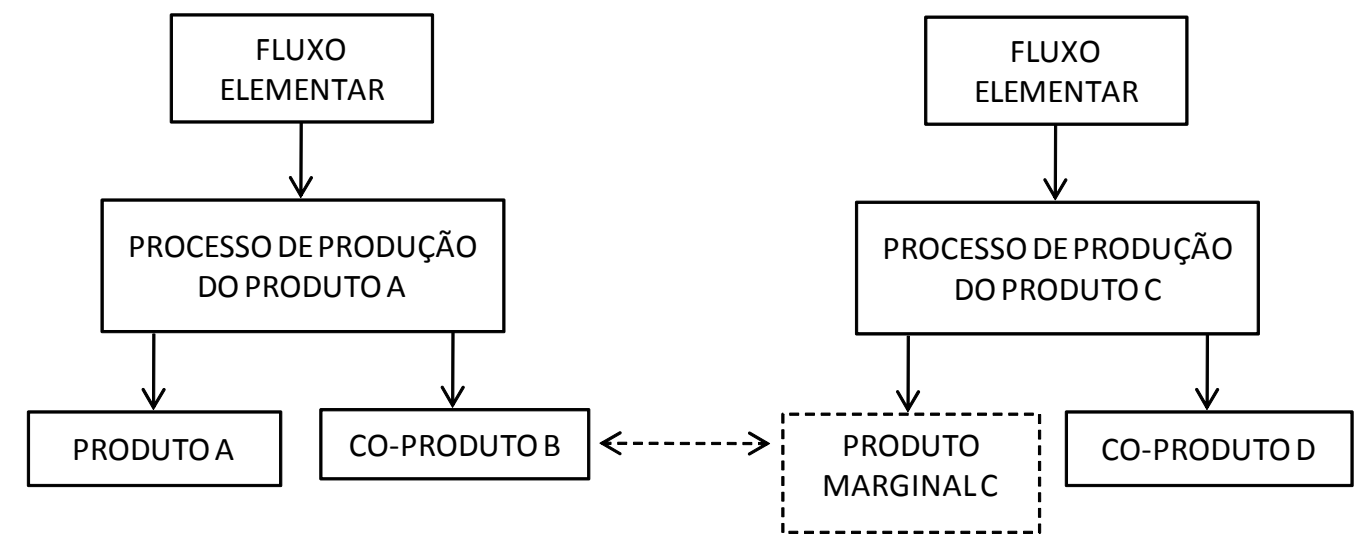

6b) Inclusão da ACV do produto marginal C pela expansão do sistema.

Figura 6 - Diferença entre os ciclos considerando a alocação e a expansão do sistema.

Na Figura 6a, o co-produto B é resultado da fabricação do produto A. Uma variação na demanda da produção de $\mathrm{B}$, pode influenciar no ciclo de vida do produto marginal $C$. Incluindo o ciclo de vida do produto marginal $C$ no ciclo de vida do produto de estudo $A$, a alocação das cargas ambientais para o produto $B$ é evitada. $\mathrm{O}$ co-produto B consta no inventário da ACV do produto A juntamente com a ACV do produto $\mathrm{C}$. 
A Figura 6b apresenta o cálculo da ACV dos produtos A e C separadamente. Neste caso, a alocação deve ser feita para as cargas referentes ao co-produto B e ao co-produto D.

Ao se decidir em expandir o sistema, deve-se levar em conta a consideração descrita na norma NBR ISO 14044 (2009b) em relação aos critérios de corte. Isso porque a seleção equivocada dos critérios de corte pode levar à exclusão de um sistema marginal relevante no sistema em estudo, mascarando os resultados.

No estudo de ACV atribucional, a vantagem do uso de um método de alocação é a separação nítida dos impactos gerados pela função em estudo de outras geradas simultaneamente pelo sistema produtivo, sem que haja a necessidade da inclusão de outros sistemas no estudo. A desvantagem quando escolhido o uso da alocação é a definição subjetiva do critério de alocação e a complexidade de atribuição de cargas em processos multifuncionais. Neste último caso, o problema da alocação ocorre quando em um processo multifuncional utilizase de uma ou mais funções para o ciclo de vida do produto em estudo, e uma diferente função (ou conjunto de funções) para os outros produtos, desde que esses não se separem fisicamente.

Muitos estudos foram feitos para ajudar na escolha do método de alocação a ser utilizado, minimizando a sua desvantagem de ter um critério subjetivo ou uma atribuição complexa de carga ambiental. Por exemplo, o trabalho de Ramirez (2009) faz uma compilação de vários métodos de alocação presentes na literatura e apresenta um fluxograma de decisão para auxílio na escolha do método a ser usado. Como outro exemplo, pode-se citar o trabalho de Heijungs e Frischknecht (1998) que examina vários casos hipotéticos e propõe uma definição precisa e operacional do problema de alocação, possibilitando, assim, uma categorização sistemática de várias abordagens que lidam com o problema da alocação.

No estudo de ACV consequencial, onde a alocação é evitada pela expansão do sistema, a vantagem deste procedimento é a anulação da subjetividade na escolha do método a ser utilizado na alocação. Com a inclusão dos sistemas marginais ao sistema estudado, o procedimento de alocação se faz desnecessário e se torna possível avaliar os sistemas que são diretamente afetados pelo uso do produto em estudo. A desvantagem da expansão do sistema é a análise de qual sistema deverá ser incluído nesta expansão, pois tal análise demandará um tempo maior no estudo e, a depender dos critérios e premissas estabelecidos para esta a 
análise, um sistema pode ser excluído ou incluído erroneamente no estudo inicial. Podem-se citar ainda como outros pontos fracos decorrentes da ampliação da fronteira, o aumento da dependência de dados confiáveis e o risco da perda da dimensão da fronteira do sistema.

\subsection{CRITÉRIO: CUSTO}

De acordo com Bezerra (1997) apud Chehebe (1997), um número cada vez maior de empresas e lideranças governamentais preocupa-se em, simultaneamente, promover desenvolvimento econômico e garantir a qualidade, sustentabilidade ambiental, mantendo o meio ambiente mais limpo e seguro.

Para a realização de estudos de ACV para auxiliar no desenvolvimento de seus processos, essas empresas e lideranças governamentais devem levar em conta o custo desprendido para tais iniciativas. Pelo fato deste tema ser relevante para a viabilidade do estudo de ACV, o custo foi escolhido como critério para análise entre os enfoques atribucional e consequencial.

O custo de uma ACV pode ser mensurado basicamente por: tempo do estudo, tamanho do estudo e quantidade de profissionais envolvidos. Pode-se dizer que a quantificação desses parâmetros está diretamente relacionada à estrutura do estudo, definida pelo seu objetivo e escopo.

No caso da ACV consequencial, a etapa de coleta dos dados predispõe como ação adicional os dados referentes aos fluxos incluídos na expansão do sistema. Consequentemente, esta diferença pode envolver também um adicional no tempo de execução e no tamanho do estudo, possuindo assim um maior custo no seu desenvolvimento.

Weidema, Fress e Nielsen (1999) afirmam que com o seu procedimento de 5 (cinco) passos apresentado no trabalho, a identificação das tecnologias marginais não se torna uma tarefa particularmente difícil. Uma vez identificada a tecnologia marginal, somente os dados ambientais para esta tecnologia deverão ser coletados, poupando muito tempo quando comparado à coleta dos dados médios, quando os dados ambientais de diversas cadeias devem ser combinadas. 
Autores como Weidema (2011) defendem que o custo de um estudo de ACV consequencial é determinado principalmente pelo custo da coleta dos dados primários. O autor defende que pelo fato dos dados pertencentes à ACV consequencial, além de serem primários, não incluem as atividades que são restritivas ao sistema, como acontece na ACV atribucional, a quantidade de dados requerida é menor, resultando, portanto, em um menor custo para o desenvolvimento do estudo consequencial.

Entretanto, um estudo de ACV atribucional também pode contar com a coleta apenas de dados primários dependendo do objetivo e escopo. Neste caso, os dados usados nos dois tipos de estudo terão as mesmas características. $\mathrm{Na}$ coincidência da procedência dos dados entre os dois enfoques, deve-se analisar a quantidade de dados necessária para a realização do estudo. O que geralmente levará ao resultado do custo da ACV consequencial ser maior pela necessidade de se contabilizar a coleta dos dados pertencentes à tecnologia marginal.

Deste ponto de vista, a ACV consequencial somente poderia ter menor custo comparada à ACV atribucional quando a primeira utilizar somente dados específicos de um sistema e a segunda, somente dados médios contabilizando a coleta de dados de inúmeros sistemas específicos íntegros para a realização da média desses dados.

\subsection{CRITÉRIO: ACURÁCIA E PRECISÃO}

Análises para conferir a confiabilidade dos resultados do estudo de ACV são recomendações constantes da NBR ISO (2009a) e NBR ISO (2009b). Segundo a NBR ISO (2009b), para se compreender melhor a significância, incerteza e sensibilidade dos resultados de uma AICV, pode ser necessário fazer uso de técnicas e informações adicionais, tais como a análise de incerteza e a análise de sensibilidade. A análise de incerteza é um procedimento para determinar como as incertezas nos dados e pressupostos se propagam nos cálculos e como afetam a confiabilidade dos resultados da AICV. Já a análise de sensibilidade é um procedimento para determinar como mudanças nos dados e nas escolhas metodológicas afetam os resultados da AICV. 
No entanto, em se tratando de analisar os diferentes enfoques da ACV, pode-se ter uma visão mais abrangente do tema confiabilidade dos resultados quando se diz respeito à modelagem mais próxima da realidade, ou seja, qual a abordagem é mais precisa modelando o sistema mais próximo à realidade. Autores como Ekvall $(2002,2004)$ propõem que a inserção da modelagem econômica, na teoria, pode modelar sistemas de produtos mais próximos à realidade, porém na prática, tal inserção pode inclui maior incerteza aos resultados da ACV. Outros como Weidema, Fress e Nielsen (1999) analisam a incerteza dos enfoques pela qualidade dos dados médios e marginais. Há ainda aqueles, como Weidema (2011), que fazem uma abordagem diferente sobre precisão e acurácia em relação aos resultados dos enfoques atribucional e consequencial da ACV.

Pelo fato da precisão do modelo quanto a representação da realidade ser relevante para a qualidade e validade do estudo de ACV, e por ainda haver questões divergentes na literatura, este tema foi escolhido como critério para análise entre os dois enfoques.

Segundo Ekvall (2002), modelos dinâmicos são uma das ferramentas que integram os conhecimentos de tecnologia e economia na modelagem de sistemas de produto. Tais modelos podem ser relevantes para ferramentas de produção mais limpa orientadas pela mudança. Em particular, tais modelos podem ser usados para gerar informação sobre efeitos marginais em sistemas de produção dinâmicos. Para o autor, pelo menos na teoria, tais informações são mais acuradas que as informações geradas por modelos estáticos.

Para Ekvall (2004) é razoável esperar que as incertezas da análise econômica sejam significativas. O autor afirma que descrever as consequências das decisões também significa enfrentar os desafios gerais de estudos futuros. O futuro é inerentemente incerto, e as consequências futuras reais de decisões são altamente incertas. Lidar com esta incerteza requer que métodos de estudos futuros sejam aplicados na ACV consequencial. As grandes incertezas também fazem com que seja impossível ou inútil estimar as consequências além das cadeias de causa e efeito. Isto implica que as fronteiras do sistema investigado sejam idealmente bem definidas no ponto onde as consequências são tão pequenas, ou as incertezas tão grandes, que outras expansões de fronteiras não trarão nenhuma informação que seja significante para qualquer decisão realista. 
Já os autores Weidema, Fress e Nielsen (1999) fazem uma comparação da incerteza em relação aos dados usados. Os autores explicam que, comparado aos dados marginais, que estão sempre relacionados a uma tecnologia bem definida, dados médios são mais incertos, pela sua incerteza inerente, resultado da combinação de um vasto número de dados de tecnologias diferentes e condições, geralmente de diferentes fontes. Esta incerteza é reforçada se os dados médios estão relacionados a um processo com mais de um produto, neste caso é necessário usar uma razão de alocação, considerada incerta pelos autores, para separar as entradas e saídas ambientais do processo entre os seus co-produtos.

Weidema (2011) apresenta a sua posição fazendo o uso de um gráfico que relaciona precisão e acurácia dos dois enfoques da ACV. De acordo com o autor, a principal fonte de incerteza em modelos consequenciais é a variabilidade real e falta de precisão dos dados utilizados. Para os modelos atribucionais, a principal fonte de incerteza é a introdução de distorções pela falta de acurácia no método, ou seja, o uso de dados médios e o uso de alocação levam a um resultado que não reflete as consequências reais da decisão estudada.

Segundo Weidema (2011), modelos atribucionais são frequentemente apresentados como tendo uma incerteza muito baixa por apenas a precisão ser mensurada, enquanto a acurácia nessa análise é ignorada. A Figura 7 apresenta um desenho esquemático, de modelo tiro ao alvo, que ilustra a diferença apresentada por Weidema (2011).

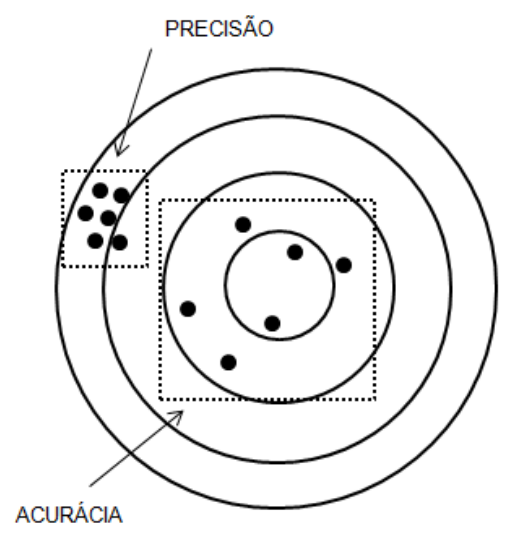

7a) Desenho esquemático para ilustrar acurácia e precisão 


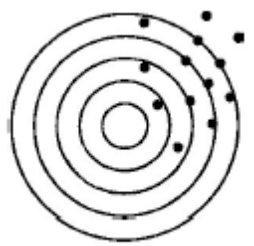

b) Baixa precisão e baixa acurácia

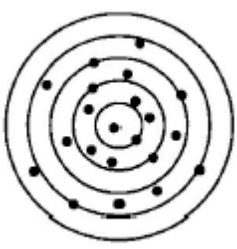

c) Baixa precisão e alta acurácia

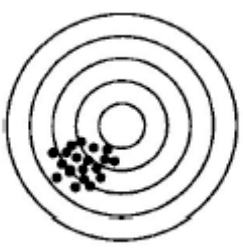

d) Alta precisão e baixa acurácia

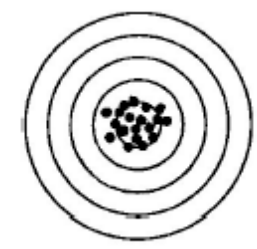

e) Alta precisão e alta acurácia

Figura 7 - Relação de acurácia e precisão para analisar os dois enfoques da ACV (Adaptado de Weidema (2011).

É possível observar na Figura 7a a diferenciação entre precisão e acurácia. Pode-se dizer que um conjunto de dados é preciso quando a diferença entre os seus valores e a sua média é pequeno. Pode-se dizer ainda que um conjunto de dados é acurado quando a diferença entre os seus valores e o valor real é pequena.

$\mathrm{Na}$ análise de Weidema (2011), os modelos atribucionais podem ser representados pela Figura 7d, possuindo alta precisão e baixa acurácia, ou seja, neste tipo de modelagem o resultado obtido podem ser precisos, porém não necessariamente condizem à realidade na qual o sistema está inserido. Já os modelos consequenciais podem ser representados pela Figura 7c, possuindo baixa precisão e alta acurácia, ou seja, seus resultados modelam melhor a realidade, porém não são precisos. Para o autor, quando medidos juntos acurácia e precisão, a modelagem consequencial tem a menor incerteza.

A análise de Weidema (2011), no entanto, pode ser questionada na definição da menor incerteza para os dois enfoques. Mesmo os modelos consequenciais sendo mais acurados por melhor modelarem a realidade com a inserção da análise econômica, se não houver precisão, a qualidade do estudo continua sendo questionada. A precisão dos dados pode ser tão pequena, ao ponto de superar a vantagem da acurácia destes modelos. Para que os dados se tornem mais precisos, devem-se aprimorar os modelos econômicos utilizados na ACV consequencial. Novos trabalhos na área econômica, como o de Pedott (2008) e Wright (2004) que estudam diversos cenários para um país em desenvolvimento, podem auxiliar nestes ajustes da modelagem econômica para que o modelo consequencial se aproxime do ideal, como a Figura 7e, tendo alta precisão além da alta acurácia. Outros trabalhos, como Deng, Babbitt e Williams (2011), Bouman et al. (2000), Sandén e Karlström (2007), Hertwich (2005), Whitefoot et al. (2011) e 
Thiesen et al. (2008), que estudam os efeitos da economia na avaliação do ciclo de vida do produto, também podem auxiliar na análise e aprimoramento da integração da ACV com diversas ferramentas econômicas.

Pode-se dizer que os modelos consequenciais são mais acurados, porém menos precisos que os modelos atribucionais. Como também pode-se dizer que os modelos atribucionais são mais precisos, porém menos acurados que os modelos consequenciais. Entretanto, não é possível dizer qual modelo é mais ou menos incerto, pois ambos possuem limitações metodológicas que fazem com que seus resultados se afastem do ideal (Figura 7e: alta precisão e alta acurácia).

\subsection{CRITÉRIO: SIMPLICIDADE DE EXECUÇÃO}

A simplicidade de execução do estudo de ACV está diretamente relacionada ao seu tempo de execução e ao seu custo. Um estudo mais simples demanda um tempo menor de execução, menor número de profissionais envolvidos e, logo, menor custo para a sua execução. Um estudo mais complexo, por sua vez, demanda um tempo maior de execução, maior número de profissionais envolvidos, muitas vezes de outras especialidades que não foram necessárias em estudos mais simples, implicando em um maior custo para a sua execução.

Para Ekvall (2002), quanto mais aspectos são incluídos em um modelo para aproximação da realidade, mais o modelo se torna complexo. Isso tende a torná-lo mais difícil de entender por que o modelo dá um resultado específico. Mesmo quando o modelo é formalmente transparente, ou seja, quando todos os dados de entrada e suas relações são apresentados, ele pode não ser transparente na prática. Isto se tornou um problema com o detalhamento dos estudos de ACV.

Assim como o custo, a simplicidade de execução dos estudos de ACV é relevante para a viabilidade desses estudos. Desta maneira, este tema foi escolhido como critério para análise entre os enfoques atribucional e consequencial.

Como já apresentado, a ACV consequencial teve início com a tentativa de se unir ferramentas econômicas com ferramentas ambientais. Apesar da melhoria na inserção dos modelos econômicos nos cálculos de ACV, a identificação da tecnologia marginal pode não ser tão trivial. Desta maneira, os avaliadores devem 
fazer simplificações e adotar premissas para considerar uma tecnologia marginal, que se feitas de maneira incorreta podem acabar invalidando o estudo. A incorporação dos sistemas marginais no estudo da ACV consequencial pode aumentar a sua complexidade, pois além de se ter um sistema adicional a ser modelado, este sistema é definido usando-se de técnicas de modelagem econômica.

A ACV atribucional pode ser considerada de maior simplicidade de execução, por não considerar a análise das tecnologias marginais, não incorporando em seu estudo a modelagem econômica. No entanto, ao não incorporar o sistema marginal com a expansão do sistema, a ACV atribucional usa o recurso de alocação para atribuir as cargas ambientais entre os seus produtos e co-produtos. $O$ uso da alocação pela ACV atribucional atribui a este enfoque uma complexidade metodológica que não é encontrada na ACV consequencial.

\subsection{CRITÉRIO: ESTABILIDADE NO TEMPO}

É válida a discussão de que os cálculos de ACV consequenciais possam ser "retrospectivos" ou "prospectivos" e, consequentemente também é válida a discussão para as ACVs atribucionais "restrospectivas" e "prospectivas", como mostrado por Sandén e Karlström (2007). Tanto os estudos de ACV consequencial como o atribucional podem fazer uso de bases históricas, atuais ou dados futuros.

A estabilidade do estudo no tempo está diretamente relacionada à qualidade do estudo. Em um estudo onde são utilizadas bases de dados históricas, a qualidade dessa base garantirá a validade do estudo. O mesmo ocorre para estudos com análise temporal futura, onde o modelo escolhido para se fazer a previsão de dados, irá garantir a validade deste estudo. Pelo fato da estabilidade do modelo no tempo, assim como a precisão do mesmo quanto à sua proximidade à realidade, ser relevante para a qualidade e validade do estudo de ACV, este tema foi escolhido como critério para análise entre os dois enfoques.

Em relação à caracterização do estudo de $\mathrm{ACV}$ na análise temporal, quando se diz que uma ACV consequencial pode ter caráter "restrospectivo", entende-se que o cálculo seria para rastrear as consequências ambientais de uma escolha histórica, quando guardadas exatamente as proporções do quadro passado com a 
circunstância atual. No entanto, mais comumente a aplicação da ACV consequencial será para avaliar as consequências ambientais futuras, utilizando as ferramentas de previsão de dados e modelos econômicos, fazendo com o este termo "consequencial retrospectivo" caia em desuso.

Por sua vez, quando se diz que uma ACV atribucional pode ter caráter "prospectivo", quer dizer que tal cálculo seria com produtos e processos em estados estacionários futuros. Entretanto, para se modelar estados estacionários futuros, seria necessário se fazer uso de ferramentas de previsão de dados para caracterizar este sistema e fazer um ajuste dos dados atuais. $O$ uso de tais ferramentas e tal ajuste de sistema futuro acabaria constituindo uma tendência em se usar nestes casos a aplicação da ACV consequencial.

Em relação às bases de dados usadas, Weidema, Fress e Nielsen (1999) defendem que uma vez que os dados marginais mudam somente com alterações nas condições de fronteira (restrições e custos de produção esperados a longo prazo) ou com desenvolvimentos na própria tecnologia marginal, os dados resultantes são mais estáveis no tempo que os dados médios correspondentes, que mudam com a menor alteração na capacidade de produção do sistema em estudo.

Em relação à previsão de dados, o uso de ferramentas estatísticas para se fazer a modelagem de sistemas futuros acrescenta ao estudo os erros inerentes a essas ferramentas. Como tanto a ACV atribucional como a consequencial podem fazer uso esta modelagem, a diferença estará na quantidade de dados utilizados, ou seja, a maior quantidade de dados possuirá maiores incertezas atribuídas ao sistema, tornando o estudo mais instável.

A ACV consequencial possui uma maior quantidade de dados por incorporar ao seu sistema as tecnologias marginais. No entanto, seus dados usados tratam-se de dados específicos e marginais, relacionados a um dado. No caso da ACV atribucional, se usados os dados médios, a previsão de dados dará a maior instabilidade ao sistema, pois cada sistema que compuser a média desses dados terá um erro atribuído quando feita a sua previsão. O resultado final será a soma desses erros. No entanto, caso sejam usados apenas dados específicos na ACV atribucional, o erro proveniente da previsão de dados será menor quando comparada à ACV consequencial, sendo o primeiro nesta comparação o enfoque mais estável no tempo. 
Trabalhos como o de Lemos (2006) auxiliam na escolha do melhor método de previsão. Utilizando a melhor ferramenta estatística, os erros embutidos na modelagem também serão minimizados.

\subsection{TABELA COMPARATIVA}

De acordo com Dalgaard et al., 2008, a ACV atribucional pode ser definida como tendo seu foco na descrição das correntes físicas de matéria e de energia, ambientalmente relevantes, de entrada e de saída do ciclo de vida de um sistema de produto ou de um seu subsistema. Já a ACV consequencial pode ser definida como tendo seu foco na descrição na forma como esses fluxos ambientalmente relevantes irão interferir em decisões futuras.

Diferenças entre as duas ferramentas foram destacadas ao longo do capítulo 4 e critérios foram selecionados para avaliá-las, discutidos nos capítulos anteriores (5.1 a 5.7). A Tabela 3 apresenta o resultado sintético destes levantamentos na forma de avaliá-los comparativamente. 
Tabela 3 - Análise das características da ACV atribucional e consequencial.

\begin{tabular}{|c|c|c|c|c|}
\hline CRITÉRIO & \multicolumn{2}{|c|}{ ACV Atribucional } & \multicolumn{2}{|c|}{ ACV Consequencial } \\
\hline \multirow[b]{2}{*}{$\begin{array}{l}\text { Fronteira do } \\
\text { Sistema }\end{array}$} & \multicolumn{2}{|c|}{ Fronteira estática e definida } & \multicolumn{2}{|c|}{$\begin{array}{c}\text { Fronteira dinâmica incluindo as tecnologias } \\
\text { marginais }\end{array}$} \\
\hline & $\begin{array}{l}\text { Vantagem: sistema simples, } \\
\text { correntes e dados bem } \\
\text { definidos }\end{array}$ & $\begin{array}{c}\text { Desvantagem: estudo } \\
\text { direcionado, enrijecimento } \\
\text { do modelo }\end{array}$ & $\begin{array}{l}\text { Vantagem: sistema } \\
\text { flexível, análise de } \\
\text { sistemas vizinhos }\end{array}$ & $\begin{array}{c}\text { Desvantagem: aumento } \\
\text { da complexidade, } \\
\text { dependência de novos } \\
\text { profissionais }\end{array}$ \\
\hline \multirow[b]{2}{*}{ Escolha dos Dados } & \multicolumn{2}{|c|}{ Uso de dados específicos do sistema ou dados médios } & \multicolumn{2}{|c|}{$\begin{array}{c}\text { Uso de dados específicos do sistema e dados } \\
\text { marginais }\end{array}$} \\
\hline & $\begin{array}{l}\text { Vantagem: maior } \\
\text { disponibilidade de dados } \\
\text { médios na literatura }\end{array}$ & $\begin{array}{l}\text { Desvantagem: inclusão de } \\
\text { tecnologias que possam } \\
\text { ser restritivas ao estudo }\end{array}$ & $\begin{array}{l}\text { Vantagem: visualização } \\
\text { da mudança marginal }\end{array}$ & $\begin{array}{l}\text { Desvantagem: erro na } \\
\text { identificação da } \\
\text { tecnologia marginal }\end{array}$ \\
\hline \multirow[b]{2}{*}{ Alocação } & \multicolumn{2}{|c|}{$\begin{array}{l}\text { Usada quando necessário com critérios de escolha do } \\
\text { tipo de alocação definidos pelo mentor do estudo }\end{array}$} & \multicolumn{2}{|c|}{$\begin{array}{c}\text { Seu uso não é necessário, pois lida com a } \\
\text { expansão do sistema }\end{array}$} \\
\hline & $\begin{array}{l}\text { Vantagem: separação nítida } \\
\text { dos impactos }\end{array}$ & $\begin{array}{l}\text { Desvantagem: definição } \\
\text { subjetiva do critério de } \\
\text { alocação }\end{array}$ & $\begin{array}{l}\text { Vantagem: anulação da } \\
\text { subjetividade na escolha } \\
\text { do método de alocação }\end{array}$ & $\begin{array}{c}\text { Desvantagem: análise } \\
\text { de qual sistema deverá } \\
\text { ser incluído na } \\
\text { expansão } \\
\end{array}$ \\
\hline Custo & $\begin{array}{c}\text { Mais custosa se } \\
\text { contabilizada a coleta dos } \\
\text { dados médios }\end{array}$ & $\begin{array}{l}\text { Menos custosa por não } \\
\text { incluir dados marginais }\end{array}$ & $\begin{array}{c}\text { Mais custosa por incluir } \\
\text { a coleta dos dados } \\
\text { marginais }\end{array}$ & $\begin{array}{c}\text { Menos custosa se } \\
\text { contabilizada somente a } \\
\text { coleta dos dados } \\
\text { específicos } \\
\end{array}$ \\
\hline Precisão & Maior precisão & Menor acurácia & Menor precisão & Maior acurácia \\
\hline $\begin{array}{l}\text { Simplicidade de } \\
\quad \text { execução }\end{array}$ & \multicolumn{2}{|c|}{ Complexidade atribuída à alocação } & \multicolumn{2}{|c|}{ Complexidade atribuída à modelagem econômica } \\
\hline $\begin{array}{l}\text { Estabilidade no } \\
\text { tempo }\end{array}$ & \multicolumn{2}{|c|}{ Menor estabilidade quando usados dados médios } & \multicolumn{2}{|c|}{ Maior estabilidade por usar dados específicos } \\
\hline
\end{tabular}




\section{CONCLUSÕES}

$\mathrm{Na}$ realização de um estudo de ACV de um produto ou serviço, as definições do objetivo e do escopo do estudo são fundamentais para a escolha do enfoque da ACV a ser aplicado. A definição da metodologia traça os caminhos a serem percorridos no estudo, desde a escolha dos dados, as delimitações do sistema, até o estudo ou não de previsões de dados. É na etapa do objetivo e escopo que seria definido qual o tipo de ACV deve ser aplicado.

Foi possível observar que há limitações metodológicas tanto para a ACV atribucional como para a ACV consequencial. No caso da ACV atribucional, por exemplo, há incertezas com relação à escolha subjetiva do método de alocação de co-produtos. Já no caso da ACV consequencial, os resultados podem ser mais sensíveis e mais suscetíveis a incertezas devido às inclusões de estudo da tendência e projeções do mercado para a escolha dos dados e tecnologias marginais e para a previsão de dados.

Com a proposição de critérios para analisar cada enfoque, ficou mais evidente a identificação dos pontos positivos e negativos na escolha de cada um deles. Ao se decidir pelo uso de determinado enfoque, o analista de ACV saberá quais os pontos que deverão receber maior cuidado na modelagem para que o seu estudo se torne o mais válido e transparente possível.

$\mathrm{Na}$ análise dos critérios, foi observado que há vantagens no uso da ACV atribucional quando se trata de um estudo onde não seja necessário o uso de alocação e que sejam usados dados específicos. $\mathrm{Na}$ análise feita, há desvantagens atribuídas ao enfoque atribucional relacionadas ao uso de dados médios em sistemas futuros e quando há alocação para os co-produtos.

Ainda não há na literatura uma padronização formal para o uso da ACV consequencial como há para a ACV atribucional. A identificação de tecnologias marginais e a inserção das novas modelagens econômicas são baseadas de acordo com o critério do analista de ACV, sem que seja necessário seguir um padrão oficializado. 
Seria difícil estabelecer um consenso em uma metodologia detalhada da ACV consequencial, pelo menos em um futuro próximo. Atualmente, não é possível aplicar a metodologia consequencial quando uma padronização detalhada da metodologia é requerida, como, por exemplo, nas chamadas declarações ambientais de produto (EPD - Environmental Product Declarations, ISO, 2006). Neste tipo de estudo, espera-se que os cálculos de ACV sejam padronizados para todos os produtos a fim de que uma comparação entre os mesmos seja possível. Se o enfoque consequencial for preferível para esta aplicação, uma solução a longo prazo seria desenvolver uma fundamentação teórica para detalhar as ACVs consequenciais e então estabelecer uma padronização baseada nesta fundamentação.

\subsection{RECOMENDAÇÕES PARA TRABALHOS FUTUROS}

Para consolidação das análises aqui apresentadas e aprofundamento dos conceitos de ACV consequencial, recomenda-se a realização de novos trabalhos que mostrem a aplicabilidade da ACV consequencial em estudos de caso e também estudos de caso comparativos das duas metodologias.

Recomenda-se também que nos grupos de pesquisa onde a ACV consequencial ainda não foi aplicada, ou se está iniciando esta atividade, que seja inserido no grupo um especialista em economia e estatística para auxílio nas modelagens econômicas e previsões de dados.

Seria interessante a realização de futuros trabalhos que aprimorem a integração da ACV com diversas ferramentas econômicas, principalmente no que diz respeito ao cenário de economias emergentes. Em particular ao cenário brasileiro, trabalhos com ACV consequencial trarão muitos frutos, pois além da análise econômica de um país em desenvolvimento, poderão ser feitas outras análises como o ILUC por se tratar também de um país predominantemente agrário. 


\section{REFERENCIAS BIBLIOGRÁFICAS}

ABNT, ASSOCIAÇÃO BRASILEIRA DE NORMAS TÉCNICAS. NBR ISO 14040: Gestão ambiental - Avaliação do ciclo de vida - Princípios e estrutura. Rio de Janeiro, 2009a.

. NBR ISO 14044: Gestão ambiental - Avaliação do ciclo de vida Requisitos e orientações. Rio de Janeiro, 2009b.

AZAPAGIC, A., CLIF, R. Allocation of environmental burdens in multiple-function systems. Journal of Cleaner Production, n.7, p. 101-119, 1999.

BOUMAN, M., HEIJUNGS, R., van der VOET, E., van den BERGHT, J. C. J. M., HUPPES, G. Material flows and economic models an analytical comparison of SFA, LCA and partial equilibrium models. Ecological Economics, n.32, p. 195-216, 2000.

BRANDER, M., TIPPER, R., HUTCHISON, C., DAVIS, G. Consequential and attribucional approaches to LCA: a guide to policy makers with specific references to greenhouse gas LCA of biofuels. Ecometrica Press, Technical Paper TP-090403-A, p. 1-14, 2009.

CHEHEBE, J. R. Análise do ciclo de vida de produtos: ferramenta gerencial da ISO 14000. QualitymarkEd., 1를. Rd. Rio de Janeiro, 1997.

CURRAN, M. A., MANN, M., NORRIS, G. The international workshop on electricity data for life cycle inventories. Journal of Cleaner Production, n.13, p. 853-862, 2005.

DALGAARD, R., SCHMIDT, J., HALBERG, N., CHRISTENSEN, P., THRANE, M., PENGUE, W. A. LCA of soybean meal. International Journal of Life Cycle Assessment, n.13, p. 240-254, 2008.

DENG, L., BABBITT, C. W., WILLIAMS, E. R. Economic-balance hybrid LCA extended with uncertainty analysis: case study of a laptop computer. Journal of Cleaner Production, n. 19, p. 1198-1206, 2011.

EARLES, J.M., HALOG, A. Consequential life cycle assessment: a review. International Journal of Life Cycle Assessment, n.16, p. 445-453, 2011 
EKVALL, T. A market-based approach to allocation at open-loop recycling. Resources, Conservation and Recycling, n. 29, p. 91-109, 2000.

EKVALL, T., FINNVEDEN, G. Allocation in ISO 14041 - a critical review. Journal of Cleaner Production, n.9, p. 197-208, 2001.

EKVALL, T. Editorial - Cleaner Production tools: LCA and beyond. Journal of Cleaner Production, n.10, p. 403-406, 2002.

EKVALL, T., WEIDEMA, B. P. System boundaries and input data in consequential life cycle inventory analysis. International Journal of Life Cycle Assessment, n. 9, p. 161-171, 2004.

EKVALL, T., TILLMAN, A. M., MOLANDER, S. Normative ethics and methodology for life cycle assessment. Journal of Cleaner Production, n.13, p. 1225-1234, 2005.

EKVALL, T., ANDRAE, A. S. Attributional and consequential environmental assessment of the shift to lead-free solders. International Journal of Life Cycle Assessment, n. 11, p. 344-353, 2006.

FINNVEDEN, G., JOHANSSON, J., LIND, P., MOBERG, G. Life cycle assessment of energy from solid waste - Part 1: General methodology and results. Journal of Cleaner Production, n.13, p. 213-220, 2005.

FINNVEDEN, G., HAUSCHILD, M. Z., EKVALL, T., GUINEÉ, J., HEIJUNGS, R., HELLWEG, S., KOEHLER, A., PENNINGTON, D., SUH, S. Recent developments in life cycle assessment. Journal of Environmental Management, n. 91, p. 1-21, 2009.

GUINÉE, J. B., HEIJUNGS, R., HUPPES, G., ZAMAGNI, A., MASONI, P., BUOMANICI, R., EKVALL, T., RYDBERG, T. Life cycle assessment: Past, present and future. Environmental Science \& Technology, v. 45, n.1, p. 90-96, 2011.

HEIJUNGS, R., FRISCHKNECHT, R. A special view on the nature of the allocation problem. The International Journal of Life Cycle Assessment, v.3, n.5, p.321-332, 1998. 
HEINTZ B, BAISNÉE P. System boundaries. In: Life cycle assessment. Workshop Report, Leiden, The Netherlands, 2-3 December 1991. SETAC, Brussels, Belgium, p. 35-52, 1992.

HERTWICH, E. Consumption and the rebound effect - an industrial ecology perspective. Journal of Industrial Ecology, v.9, n. 1-2, p. 85-98, 2005.

ISO, INTERNATIONAL ORGANIZATION FOR STANDARDIZATION, ISO 14025: Environmental labels and declarations - Type III environmental declarations Principles and procedures, ISO, Genebra, 2006.

LEMOS, F. O. Metodologia para seleção de métodos de previsão de demanda. 183p. Dissertação (Mestrado). Universidade Federal do Rio Grande do Sul. Porto Alegre, 2006.

LESAGE, P., DESCHÊNES, L., SAMSON, R. Evaluating holistic environmental consequences of brownfield management options using consequential life cycle assessment for different perspectives. Environ Manage, n.40, p. 323-337, 2007.

LESAGE, P., EKVALL, T., DESCHÊNES, L., SAMSON, R. Environmental assessment of brownfield rehabilitation using two different life cycle inventory models. Part 1: Methodological approach. International Journal of Life Cycle Assessment, n. 12, p. 391-398, 2007a.

LESAGE, P., EKVALL, T., DESCHÊNES, L., SAMSON, R. Environmental assessment of brownfield rehabilitation using two different life cycle inventory models. Part 2: Case study. International Journal of Life Cycle Assessment, n. 12, p. 497-513, 2007b.

LUND, H., MATHIESEN, B.V., CHRISTENSEN, P. Energy system analysis of marginal electricity supply in consequential LCA. International Journal of Life Cycle Assessment, n.15, p. 260-271, 2010.

MATHIESEN, B.V., MÜNSTER, M., FRUERGAARD, T. Uncertainties related to the identification of the marginal energy technology in consequential life cycle assessments. Journal of Cleaner Production, n. 17, p. 1331-1338, 2009.

PEDOTT, M., Perspectivas para o crescimento econômico do Brasil em diferentes cenários. 126p. Dissertação (Mestrado). Pontifícia Universidade Católica do Rio Grande do Sul. Porto Alegre, 2008. 
RAMIREZ, P. Análise de Métodos de Alocação Utilizados em Avaliação do Ciclo de Vida. 138p. Dissertação (Mestrado). Universidade Federal de Santa Catarina. Florianópolis, 2009.

REINHARD, J., ZAH, R. Global environmental consequences of increased biodiesel consumption in Switzerland: consequential life cycle assessment. Journal of Cleaner Production, n. 17, p. S46-S56, 2009.

RIBEIRO, P. H. Contribuição ao banco de dados brasileiro para apoio a avaliação do ciclo de vida: fertilizantes nitrogenados. 341p. Tese (Doutorado). Escola Politécnica da Universidade de São Paulo, Departamento de Engenharia Química. São Paulo, 2009.

SANDÉN, B. A., KARLSTRÖM, M. Positive and negative feedback in consequential life cycle assessment. Journal of Cleaner Production, n.15, p. 1469-1481, 2007.

SCHMIDT, J. H. Comparative life cycle assessment of rapeseed oil and palm oil. International Journal of Life Cycle Assessment, n.15, p. 183-197, 2010.

SEARCHINGER, T., Heimlich, R., Houghton, A., Dong, F., Elobeid, A., Fabiosa, J., Tokgoz, S., Hayes, D., Yu, T. Use of U.S. croplands for biofuels increases greenhouse gases through emissions from land-use change. Science, n.319, p. 1238-1240, 2008.

THIESEN, J., CHRISTENSEN, T. S., KRISTENSEN, T. G., ANDERSEN, R. D., BRUNOE, B., GREGERSEN, T. K., THRANE, M., WEIDEMA, B. Rebound effects of price differences. International Journal of Life Cycle Assessment, v. 13, n.2, p. 104-114, 2008.

THOMASSEN, M. A., DALGAARD, R., HEIJUNGS, R., BOER, I., Attributional and consequential LCA of milk production. International Journal of Life Cycle Assessment, n. 13, p. 339-349, 2008.

TILLMAN, A. M. Significance of decision-making for LCA methodology. Environmental Impact Assessment Review, n.20, p. 113-123, 2000.

UNIÃO EUROPEIA. ILCD Handbook - International Reference Life Cycle Data System - General Guide for Life Cycle Assessment - Detailed Guidance. European Commission, Joint Research Centre, Institute for Environment and Sustainability, 2010. 
WEIDEMA, B. Application typologies for life cycle assessment. International Journal of Life Cycle Assessment, n. 3, p. 237-240, 1998.

WEIDEMA, B. System expansions to handle co-products of renewable materials. In: $7^{\text {th }}$ LCA Case Studies Symposium. Presentations Summaries, p. 45-48, 1999.

WEIDEMA, B., FRESS, N., NIELSEN, A-M. Marginal production technologies for life cycle inventories. International Journal of Life Cycle Assessment, n. 4, p. 48-56, 1999.

WEIDEMA, B. Market information in life cycle assessment. Environmental Project n. 863. Danish Environmental Protection Agency, Copenhagen, Denmark, 2003.

WEIDEMA, B. Guidelines for applications of deepened and broadened LCA, Deliverable D18 of WP5, CALCAS Project, 2009.

WEIDEMA, B. Consequential LCA - Understanding the consequence of change myths and reality. São Paulo, 16 nov. 2011. Palestra proferida por ocasião do curso ministrado pela Associação Brasileira do Ciclo de Vida "ACV Consequencial", São Paulo, 2011.

WHITEFOOT, K. S., GRIMES-CASEY, H. G., GIRTA, C. E., MORROW, W. R., WINEBRAKE, J. J., KEOLEIAN, G. A., SKERLOS, S. J. Consequential life cycle assessment with market-driven design - development and demonstration. Journal of Industrial Ecology, v. 15, n. 5, p. 726-742, 2011.

WRIGHT, J. T. C., PEREIRA, A. M., Levantamento e análise de métodos de elaboração de cenários nas empresas brasileiras. In: SEMEAD - SEMINÁRIOS DE ADMINISTRAÇÃO FEA/USP, 7., 2004, São Paulo. Resumo dos trabalhos. São Paulo: USP, 2004. Disponível em <http://www.ead.fea.usp.br/semead/7semead/>. Acesso em: 18 dez. 2011. 


\section{GLOSSÁRIO}

As definições relacionadas neste glossário foram extraídas das normas ABNT ISO NBR 14040 (2006a) e ABNT ISO NBR 14040 (2006b), exceto quando há outra referência bibliográfica indicada.

Alocação - repartição dos fluxos de entrada ou saída de um processo ou sistema de produto entre o sistema de produto em estudo e outro(s) sistema(s) de produto

Análise de incerteza - procedimento sistemático para quantificar a incerteza introduzida nos resultados de uma análise de inventário do ciclo de vida pelos efeitos cumulativos da imprecisão dos modelos, incerteza das entradas e variabilidade dos dados. Tanto distribuições de probabilidade quanto faixas de probabilidade são utilizadas para determinar a incerteza dos resultados.

Análise de sensibilidade - procedimentos sistemáticos para estimar os efeitos das escolhas feitas em termos de métodos e dados nos resultados de um estudo.

Aspecto ambiental - elemento das atividades, produtos ou serviços de uma organização que pode interagir com o meio ambiente.

Avaliação - elemento incluído na fase de interpretação do ciclo de vida que visa a estabelecer a confiabilidade dos resultados da avaliação do ciclo de vida. O elemento avaliação inclui a verificação de completeza, verificação de sensibilidade, verificação de consistência e qualquer outra validação que possa ser requerida de acordo com a definição do objetivo e escopo do estudo.

Categoria de impacto - classe que representa as questões ambientais relevantes às quais os resultados da análise do inventário do ciclo de vida podem ser associados. 
Critérios de corte - especificação, em termos de fluxos de material ou energia ou do nível de significância ambiental associados a processos elementares ou a sistemas de produto, dos limites que definem a exclusão de dados de um estudo.

Co-produto - qualquer um dentre dois ou mais produtos procedentes do mesmo processo elementar ou sistema de produto.

Energia de processo - entrada de energia requerida para operar o processo ou equipamento dentro de um processo elementar, excluindo as entradas de energia para produção e distribuição da própria energia.

Entrada - fluxo de produto, material ou energia que entra em um processo elementar. Materiais e produtos incluem matérias primas, produtos intermediários e co-produtos.

Fluxo de energia - entrada ou saída de um processo elementar ou sistema de produto quantificada em unidades de energia. $O$ fluxo de energia de entrada pode ser chamado entrada de energia; o fluxo de energia de saída pode ser chamado saída de energia.

Fluxo de produto - entrada ou saída de produtos provenientes de ou com destino a um outro sistema de produto.

Fluxo de referência - medida das saídas de processos em um dado sistema de produto requeridas para realizar a função expressa pela unidade funcional.

Fluxo elementar - material ou energia retirado do meio ambiente e que entra no sistema em estudo sem sofrer transformação prévia por interferência humana, ou material ou energia que é liberado no meio ambiente pelo sistema em estudo sem sofrer transformação subsequente por interferência humana

Fluxo intermediário - fluxo de produto, material ou energia que ocorre entre processos elementares do sistema de produto em estudo. 
Fronteira do sistema - conjunto de critérios que especificam quais processos elementares fazem parte de um sistema de produto.

Impacto ambiental - consumo de recursos, liberações de poluentes e resíduos gerados por atividades tecnológicas (ELVALL; FINNVEDEN, 2001).

Liberações - emissões para a atmosfera e descargas para corpos d'água e para o solo.

Matéria-prima - material primário ou secundário que é utilizado para produzir um produto. Material secundário inclui material reciclado.

Parte interessada - indivíduo ou grupo que tem interesse ou é afetado pelo desempenho ambiental de um sistema de produto ou pelos resultados da avaliação do ciclo de vida.

Processo - conjunto de atividades inter-relacionadas ou interativas que transformam entradas em saídas.

Processo elementar - menor elemento considerado na análise de inventário do ciclo de vida para o qual dados de entrada e saída são quantificados.

Produto intermediário - saída de um processo elementar que se constitui em entrada para um outro processo elementar e que requer transformação adicional dentro do sistema de produto.

Qualidade dos dados - características dos dados que se relacionam à sua capacidade de satisfazer requisitos estabelecidos.

Resíduo - substâncias ou objetos os quais o detentor pretende ou é obrigado a dispor. 
Resultado da análise do inventário do ciclo de vida - Resultado do ICV resultado de uma análise de inventário do ciclo de vida que registra os fluxos que cruzam a fronteira do sistema e que provê o ponto de partida para a avaliação de impacto do ciclo de vida.

Saída - fluxo de produto, material ou energia que deixa um processo elementar. Materiais e produtos incluem matérias primas, produtos intermediários, co-produtos e liberações.

Sistema de produto - conjunto de processos elementares, com fluxos elementares e de produto, desempenhando uma ou mais funções definidas e que modela o ciclo de vida de um produto.

Subsistema - conjunto de processos elementares que é uma parte do sistema definido (VIGON, 1993 apud RIBEIRO, 2009).

Unidade funcional - desempenho quantificado de um sistema de produto para utilização como uma unidade de referência.

Verificação de completeza - processo para verificar se as informações derivadas das fases precedentes de uma avaliação do ciclo de vida são suficientes para se chegar a conclusões de acordo com a definição de objetivo e escopo.

Verificação de consistência - processo para verificar, antes de se consolidar as conclusões do estudo, se os pressupostos, métodos e dados são aplicados de forma consistente ao longo do estudo e se estão de acordo com a definição de objetivo e escopo.

Verificação de sensibilidade - processo para verificar se as informações obtidas através de uma análise de sensibilidade são relevantes para se chegar às conclusões e emitir recomendações. 


\section{ANEXO A - Procedimento para identificação da tecnologia marginal}

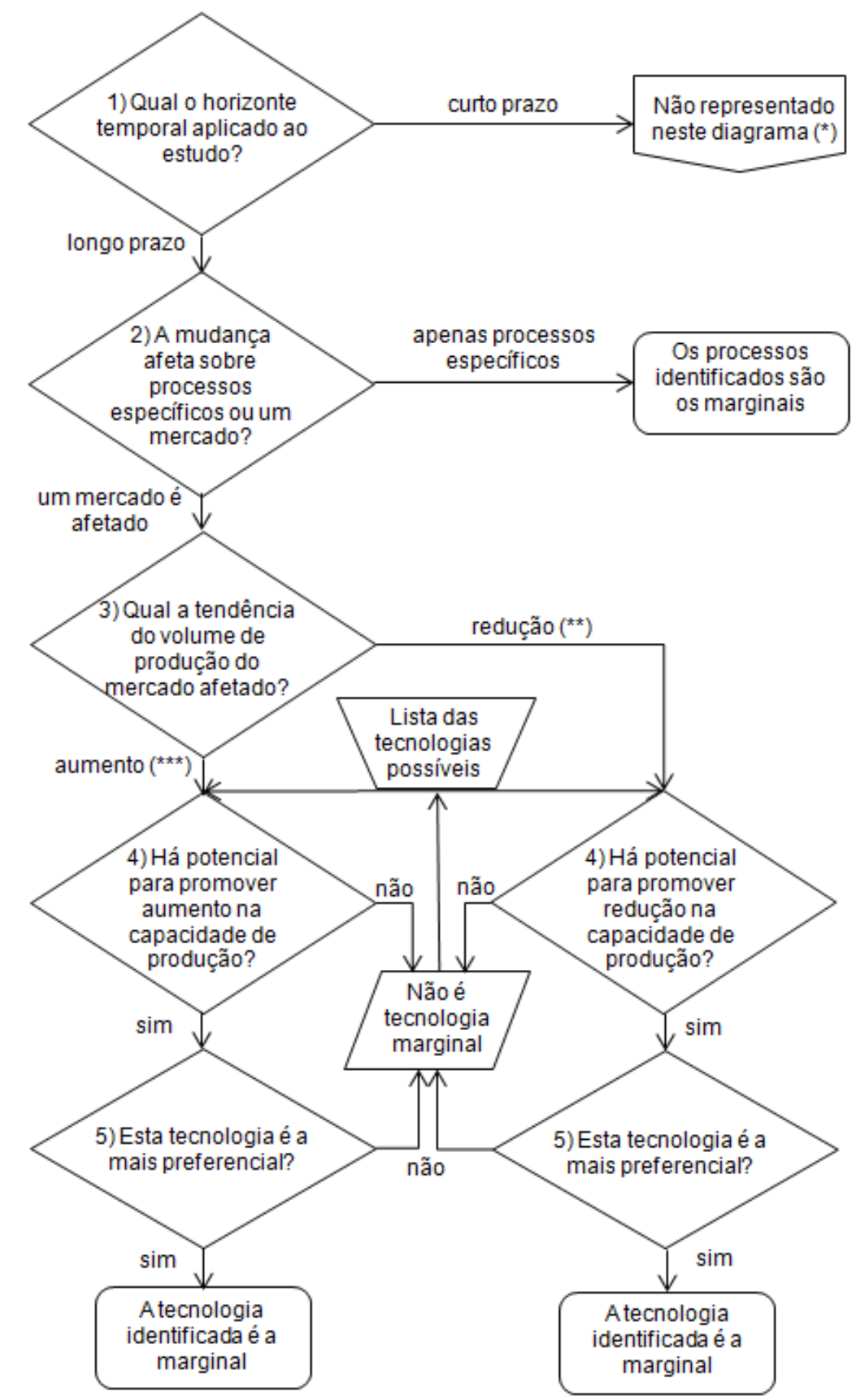

$\left.{ }^{\star}\right)$ Horizontes a curto prazo marginais podem ser identificados usando uma árvore de decisão similar à representada nesta figura. A diferença entre os diagramas será que ao invés do aumento ou decréscimo na capacidade, o diagrama a curto prazo responderá por aumentos ou decréscimos na saída de produção dentro da capacidade existente.

$\left({ }^{* *}\right)$ Para ser preciso, a opção "redução" é apenas relevante se o volume de mercado é mais decrescente que a redução resultante da retirada gradual planejada e regular dos bens capitais. Consequentemente, a opção "aumento" é também válida quando os volumes de mercado decrescem a uma razão menor que a razão regular de reposição de capital.

$\left.{ }^{* \star *}\right)$ A preferência implicada aqui é relacionada com os esperados custos de produção a longo prazo levando em conta todos as externalidades relevantes para aquele que decide sobre o ajuste da capacidade.

Figura 8 - Árvore de decisão mostrando o procedimento de cinco passos (adaptado de Weidema, Fress e Nielsen (1999). 


\section{ANEXO B - Critérios de seleção para métodos de previsão}

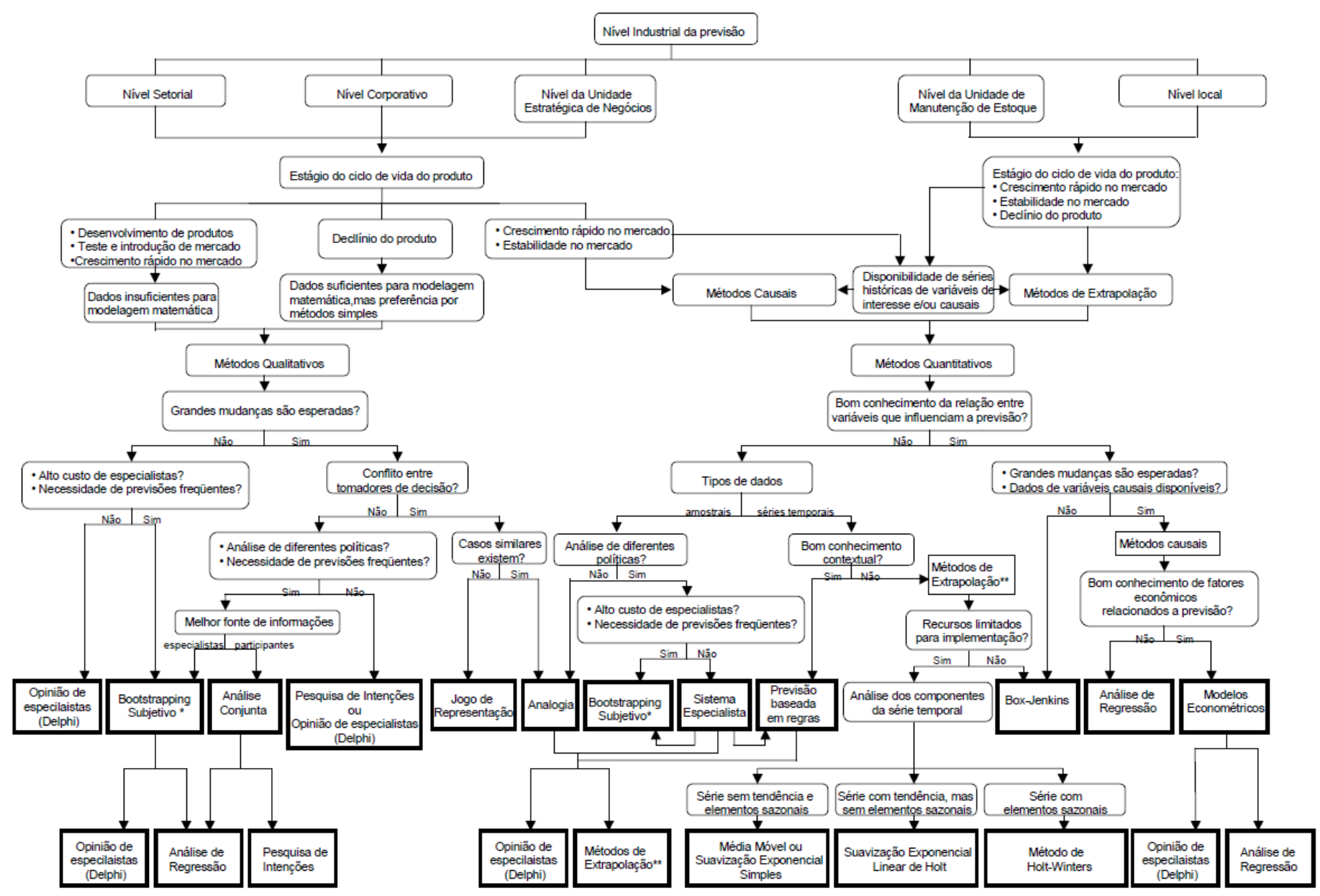

Figura 9 - Fluxograma para a escolha de métodos de previsão (LEMOS, 2006). 


\section{ANEXO C - Aplicações da ACV Consequencial}

Tabela 4 - Exemplos de casos de estudo de ACV consequencial e os modelos econômicos utilizados.

\begin{tabular}{|c|c|c|c|c|c|c|c|c|}
\hline Referência & Tópico/Tema & $C \times A$ & SWA & PEM & MMMR-PEM & CGE & ILUC & $\mathrm{RE}$ \\
\hline Hofstetter e Norris (2003) & Saúde ocupacional & $S$ & $\mathrm{~N}$ & $\mathrm{~N}$ & $\mathrm{~N}$ & $\mathrm{~N}$ & $\bar{N}$ & S \\
\hline Weidema (2003) & Tópicos múltiplos & $\mathrm{N}$ & $S$ & $\mathrm{~N}$ & $\mathrm{~N}$ & $\mathrm{~N}$ & $\bar{N}$ & $\mathrm{~N}$ \\
\hline Ekvall e Andrae (2006) & Eletrônicos & $\mathrm{S}$ & S & S & $\mathrm{N}$ & $\mathrm{N}$ & $\mathrm{N}$ & $\mathrm{N}$ \\
\hline Thrane (2006) & Pesca & $\mathrm{N}$ & $\mathrm{S}$ & $\bar{N}$ & $\mathrm{~N}$ & $\mathrm{~N}$ & $\mathrm{~N}$ & $\mathrm{~N}$ \\
\hline Lesage et al. (2007a) & $\begin{array}{l}\text { Terrenos industriais abandonados } \\
\text { ("brownfields") }\end{array}$ & $\mathrm{N}$ & $\mathrm{N}$ & $\mathrm{s}$ & $\mathrm{N}$ & $\mathrm{N}$ & $\mathrm{N}$ & $\mathrm{N}$ \\
\hline Lesage et al. (2007b) & $\begin{array}{c}\text { Terrenos industriais abandonados } \\
\text { ("brownfields") }\end{array}$ & $\mathrm{s}$ & $\mathrm{N}$ & $\mathrm{s}$ & $\mathrm{N}$ & $\mathrm{N}$ & $\mathrm{N}$ & $\mathrm{N}$ \\
\hline Eriksson et al. (2007) & Aquecimento & $\mathrm{N}$ & $\mathrm{N}$ & $\mathrm{N}$ & $\mathrm{N}$ & $\mathrm{N}$ & $\mathrm{N}$ & $\mathrm{N}$ \\
\hline Sandén e Karlstrom (2007) & Combustíveis renováveis & $\mathrm{N}$ & $\mathrm{S}$ & $\mathrm{N}$ & $\mathrm{N}$ & $\mathrm{N}$ & $\mathrm{N}$ & $\mathrm{N}$ \\
\hline Schmidt et al. (2007) & Papel & $\mathrm{N}$ & S & $\mathrm{N}$ & $\mathrm{N}$ & $\mathrm{N}$ & $\mathrm{N}$ & $\mathrm{N}$ \\
\hline Spielmann et al. (2008) & Transporte coletivo & $\mathrm{N}$ & $\mathrm{N}$ & $\mathrm{N}$ & $\mathrm{N}$ & $\mathrm{N}$ & $\mathrm{N}$ & $S$ \\
\hline Thiesen et al. (2008) & Bens de consumo & $\mathrm{N}$ & $\mathrm{N}$ & $\mathrm{N}$ & $\mathrm{N}$ & $\mathrm{N}$ & $\mathrm{N}$ & $S$ \\
\hline Kloverpris et al. (2008) & Agricultura & $\mathrm{N}$ & $\mathrm{N}$ & $\mathrm{N}$ & $\mathrm{N}$ & S & $S$ & $\mathrm{~N}$ \\
\hline Dalgaard et al. (2008) & Agricultura & $\mathrm{N}$ & $\mathrm{N}$ & $S$ & $S$ & $\mathrm{~N}$ & $\mathrm{~N}$ & $\mathrm{~N}$ \\
\hline Schmidt e Weidema (2008) & Agricultura & $\mathrm{N}$ & $S$ & $\mathrm{~N}$ & $\mathrm{~N}$ & $\mathrm{~N}$ & $S$ & $\mathrm{~N}$ \\
\hline Schmidt (2008a) & Agricultura & $\mathrm{N}$ & $S$ & $\mathrm{~N}$ & $\mathrm{~N}$ & $\mathrm{~N}$ & $S$ & $\mathrm{~N}$ \\
\hline Schmidt (2008b) & Agricultura & $\mathrm{N}$ & $S$ & $S$ & $\mathrm{~N}$ & $\mathrm{~N}$ & $S$ & $\mathrm{~N}$ \\
\hline Thomassen et al. (2008) & Agricultura & $S$ & $S$ & $S$ & $\mathrm{~N}$ & $\mathrm{~N}$ & $S$ & $\mathrm{~N}$ \\
\hline
\end{tabular}




\begin{tabular}{|c|c|c|c|c|c|c|c|c|}
\hline Referência & Tópico/Tema & $C \times A$ & SWA & PEM & MMMR-PEM & CGE & ILUC & $\mathrm{RE}$ \\
\hline Frees (2008) & Metais & $\mathrm{N}$ & $\mathrm{N}$ & $S$ & $\mathrm{~N}$ & $\mathrm{~N}$ & $\mathrm{~N}$ & $\mathrm{~N}$ \\
\hline Pehnt et al. (2008) & Eletricidade & $\mathrm{N}$ & $\mathrm{N}$ & $\mathrm{N}$ & $\mathrm{N}$ & $\mathrm{N}$ & $\mathrm{N}$ & $\mathrm{N}$ \\
\hline Searchinger et al. (2008) & Biocombustíveis & $\mathrm{N}$ & $\mathrm{N}$ & $S$ & $S$ & $\mathrm{~N}$ & $S$ & $\mathrm{~N}$ \\
\hline Vieira e Horvath (2008) & Edifícios & $S$ & $S$ & $S$ & $\mathrm{~N}$ & $\mathrm{~N}$ & $\mathrm{~N}$ & $\mathrm{~N}$ \\
\hline Kløverpris (2009) & Agricultura & $\mathrm{N}$ & $\mathrm{N}$ & $\mathrm{N}$ & $\mathrm{N}$ & $S$ & $S$ & $\mathrm{~N}$ \\
\hline Reinhard e Zah (2009) & Biocombustíveis & $S$ & $S$ & $S$ & $\mathrm{~N}$ & $\mathrm{~N}$ & $S$ & $\mathrm{~N}$ \\
\hline Silalertruksa et al. (2009) & Biocombustíveis & $\mathrm{N}$ & $S$ & $S$ & $\mathrm{~N}$ & $\mathrm{~N}$ & $S$ & $\mathrm{~N}$ \\
\hline US EPA (US 2010) & Biocombustíveis & $\mathrm{N}$ & $\mathrm{N}$ & $S$ & $\mathrm{~S}$ & $\mathrm{~S}$ & $S$ & $\mathrm{~N}$ \\
\hline Kloverpris et al. (2010) & Agricultura & $\mathrm{N}$ & $\mathrm{N}$ & $\mathrm{N}$ & $\mathrm{N}$ & $\mathrm{S}$ & $\mathrm{S}$ & $\mathrm{N}$ \\
\hline
\end{tabular}

CxA - Comparação de ACV atribucional e consequencial

SWA - Uso do método passo a passo para identificação da tecnologia afetada (step-wise approach, WEIDEMA; FRESS; NIELSEN, 1999)

PEM - Uso do modelo de equilíbrio parcial

MMMR-PEM - Uso do modelo de equilíbrio parcial multi-mercado e muti-regional

CGE - Uso do modelo de equilíbrio geral computável

ILUC - Análise da mudança indireta do uso do solo

$\mathrm{RE}$ - Análise dos efeitos ricochetes

Fonte: Earles e Halog, 2011. 


\section{ANEXO D - Estudo de caso ACV Consequencial}

Neste anexo é apresentado um resumo do estudo de caso de ACV consequencial de soldas sem chumbo realizado por Ekvall e Andrae (2006).

\section{Definição do objetivo}

Os principais objetivos do trabalho foram: (i) demonstrar e comparar as metodologias ACV atribucional $^{4}$ e consequencial; (ii) contribuir para a avaliação ambiental da mudança global da pasta de solda comum de estanho e chumbo para uma das mais comuns pastas de solda sem chumbo.

\section{Definição do escopo}

Enfoques: Atribucional e consequencial.

Unidade funcional: volume de pasta de solda necessária para montar componentes em uma placa de circuito impresso (PWB - Printed Wiring Board) comum (aproximadamente $300 \mathrm{~mm}^{3}$ ).

A Figura 9 apresenta uma estrutura esquemática do ciclo de vida consequencial onde o produto marginal definido foi a sucata de chumbo, a modelagem econômica usada foi equilíbrio parcial.

Como considerações, podem-se ressaltar: exclusão da fase de uso do produto eletrônico; os metais provenientes do desmonte das placas impressas (PBA - Printed Board Assembly) foram considerados como matéria-prima de outros ciclos de vida e não como resíduo. Além disso, o mercado de eletricidade foi excluído do inventário da ACV consequencial.

\footnotetext{
${ }^{4}$ Mesmo que um dos objetivos do trabalho de Ekvall e Andrae (2006) seja a comparação entre os enfoques atribucional e consequencial, neste Anexo será apresentado somente o estudo de ACV consequencial.
} 


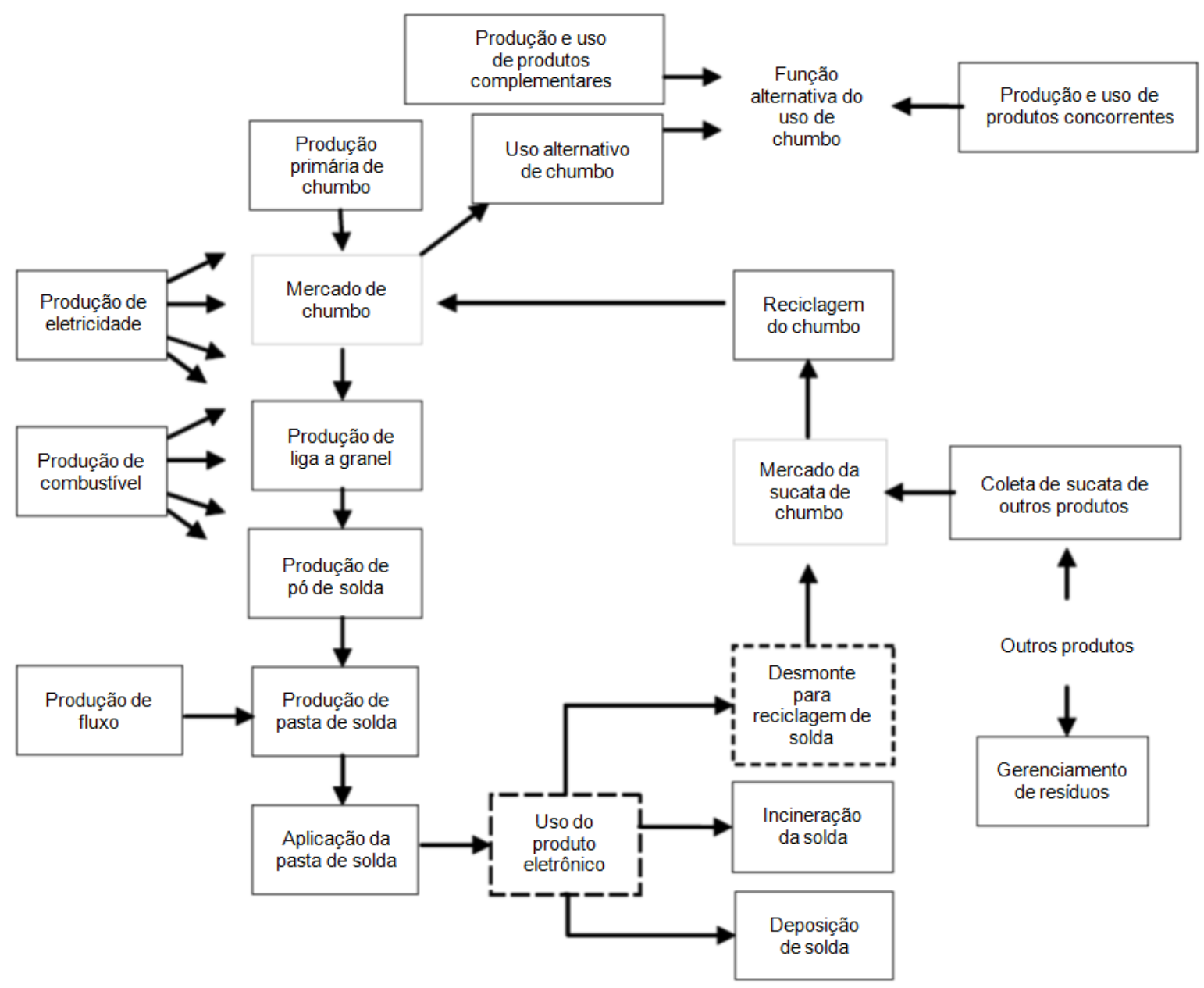

Figura 9 - Estrutura esquemática das pastas de solda de chumbo e estanho e das pastas de solda sem chumbo para a modelagem consequencial (EKVALL; ANDRAE, 2006)

Para a ACV atribucional, não são consideradas as etapas de mercado de chumbo, a inclusão dos produtos marginais e a reciclagem de chumbo, como mostrado na Figura 10. 


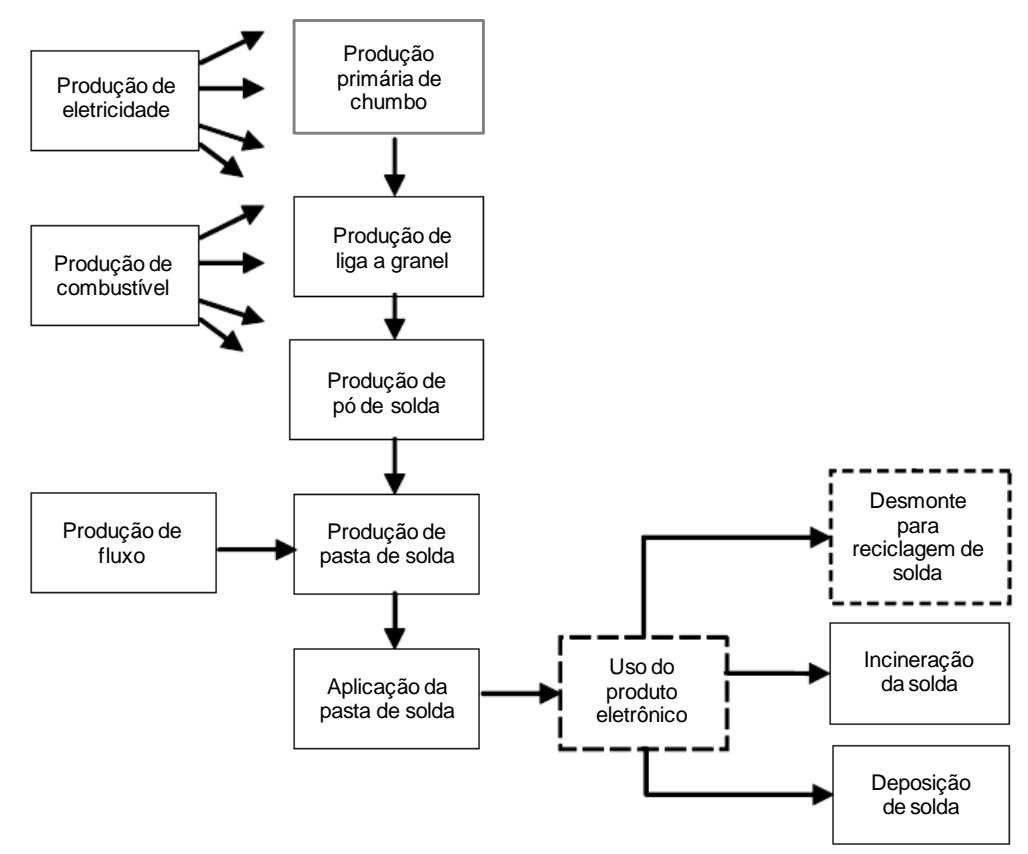

Figura 10 - Estrutura esquemática das pastas de solda de chumbo e estanho e das pastas de solda sem chumbo para a modelagem atribucional (EKVALL; ANDRAE, 2006)

\section{Inventário consequencial}

O estudo diz respeito à mudança global de uma pasta de solda para outra. Soldas são produzidas e aplicadas em todo o mundo, e metais, energias motrizes e produtos eletrônicos são negociados em mercados internacionais. Uma mudança na demanda de metal, energia motriz, etc, no ciclo de vida da solda irá afetar os mercados internacionais na sua margem. Assim, o objetivo inicial da qualidade dos dados para muitos dos subsistemas do ICV consequencial foi o uso de dados marginais globais. Os dados realmente usados no ICV foram mais ou menos representativos de dados encontrados na literatura ou dados de fornecedores individuais, devido ao fato que seus dados marginais não estarem disponíveis. Um problema encontrado foi que os conjuntos de dados disponíveis incluíam diversas lacunas para emissões de chumbo. No fim, foram usadas estimativas gerais da literatura para calcular aproximadamente as emissões de chumbo.

Foram estimadas as mudanças na produção e no uso alternativo de chumbo e sucata de chumbo baseada na elasticidade estimada do preço do suprimento e demanda para um dos bens. 
O estudo foi focado na elasticidade a longo prazo, pois os autores acreditavam que as análises dos sistemas ambientais são conduzidas principalmente devido à preocupação com o futuro ambiente a um longo prazo.

\section{Produção de eletricidade marginal}

Devido à falta de dados sobre a média ponderada de eletricidade marginal, foram utilizados dados sobre a produção de eletricidade média a nível mundial para modelar a produção de eletricidade no ICV consequencial.

\section{Produção de metal marginal}

Neste estudo não foi possível identificar claramente uma tecnologia marginal, pois uma combinação de várias tecnologias é usada no modelo atual. $\mathrm{Na}$ ausência de dados sobre a produção de chumbo marginal, foram usados os mesmos dados de entrada como no ICV atribucional. Isto também foi aplicado para os outros metais.

\section{Uso do chumbo marginal}

A conclusão dos autores sobre o uso do chumbo marginal é que uma mudança de soldas com chumbo para as sem chumbo provavelmente resultará no aumento do uso de chumbo em uma mistura de outros produtos. Esta mistura é provavelmente dominada por baterias, porque a maior parte do chumbo é atualmente usada em baterias, e uma mudança no preço do chumbo pode afetar significativamente a competitividade atual e futura das baterias.

Neste estudo, assumem-se para o uso alternativo de chumbo as baterias de ácido-chumbo; para os produtos complementares, as células fotovoltaicas; e para os produtos concorrentes de eletricidade, os produzidos pelos geradores de diesel. A produção, uso e gerenciamento de resíduos destes produtos foram incluídos no ICV consequencial. 


\section{Mercado de chumbo}

Os autores assumiram que as elasticidades de preço do suprimento e da demanda são bastante baixos. Para eles, não foi encontrada nenhuma razão para alegar que uma é mais elevada que a outra. No modelo de ICV, o suprimento e a demanda são igualmente elásticos. Isto significa que para cada tonelada de chumbo que é eliminada a partir das soldas, a produção de chumbo é reduzida por 0,5 tonelada e o uso de chumbo em outros produtos é acrescida de 0,5 tonelada. A incerteza nesta parte do modelo é grande.

Reciclagem de chumbo marginal

Não foi possível nesse estudo identificar uma tecnologia marginal específica para a reciclagem de chumbo. Ao invés disto, foram usados dados de uma produção local.

Gerenciamento de resíduo de chumbo marginal

O gerenciamento de resíduo de chumbo marginal para os produtos de chumbo, além dos produtos eletrônicos, é provável que seja feita em aterros sanitários, pois são mais baratos que a incineração. O chumbo que entra no mercado de sucata de chumbo é proveniente das placas de circuito impresso onde as soldas de estanho e chumbo foram usadas, e de outros produtos de chumbo reciclados. Além disso, há uma diferença importante entre os depósitos simples e aterros devidamente gerenciados com controle de chorume. Cinzas contendo chumbo a partir das plantas de incineração também devem ser contabilizadas. A cinza tóxica deve ser gerenciada de forma adequada.

\section{Mercado de sucata de chumbo}

Assumiu-se que a coleta das sucatas de placas impressas com soldas de chumbo e estanho afeta não só o uso de sucata de chumbo, como também a coleta de sucata de chumbo de outros produtos. Estimativas quantitativas da elasticidade de preço do suprimento e da demanda são difíceis de obter para a sucata de 
chumbo. Os autores assumiram que as elasticidades iguais, ou seja, que a demanda e a oferta do mercado são igualmente afetados por pequenas mudanças no preço do chumbo.

\section{Resultados do ICV}

O ICV consequencial difere do ICV atribucional por incluir o mercado de chumbo, o uso alternativo do chumbo e seus produtos complementares e concorrentes. O ICV consequencial também inclui a reciclagem de chumbo, 0 mercado de sucata de chumbo e o gerenciamento de resíduos das fontes de sucata de chumbo. O ICV consequencial das soldas sem chumbo é idêntico ao ICV consequencial das soldas sem chumbo.

Os resultados de emissões de chumbo refletem somente aos dos produtos de chumbo, o que significa que as emissões de chumbo de produtos como eletricidade e materiais auxiliares não estão incluídos nestes resultados. Os resultados de chumbo no ICV consequencial da solda com estanho e chumbo são dominados pelas emissões provenientes do ciclo de vida da solda. As emissões evitadas a partir do ciclo de vida da bateria são menores. 